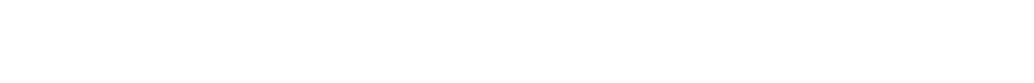

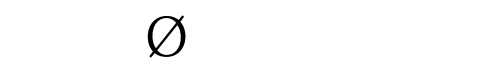

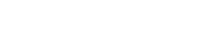

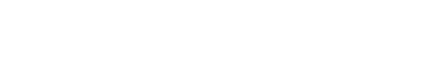 \\ ř \\ rŮt ŤKE
}

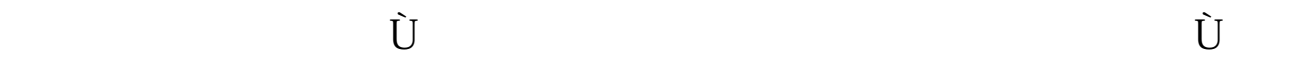

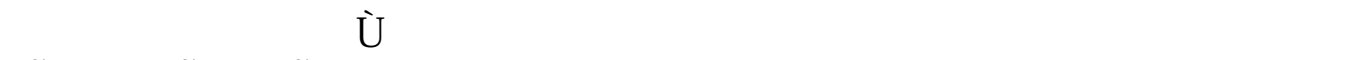

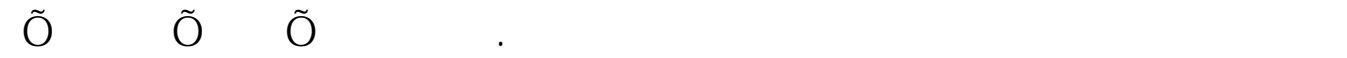

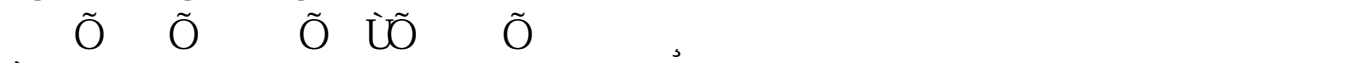

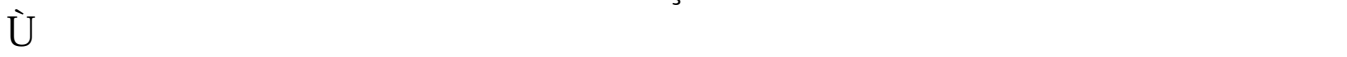

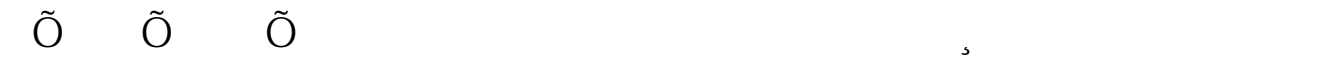

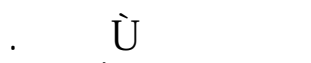

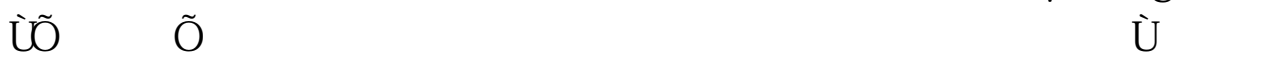

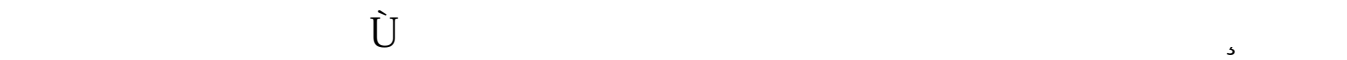

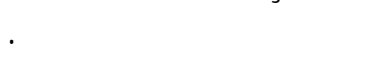

\section{THE CONSTANT \& VARIABLE IN FORMAL CHARACTERISTICS OF OLD MOSUL CITY MOSQUES}

\author{
Dhuha Abdul Gani Abdul Aziz \\ Assistant Lecturer
}

\author{
Rabee Khaleel Thanoon \\ M.Sc
}

\begin{abstract}
The research focused on studying the specialty of mosque architectures in old Mosul City as theoretical knowledge can be used by architect in designing mosques that have its origins in the traditional model of mosques. The research adopted typology to analyze models of Mosul traditional mosques, focusing on its formal characteristics by inducing the apparent characteristics related to plans and elevations, and essential characteristics related to movement system.
\end{abstract}

The research concluded the constant characteristics of mosque architecture in old Mosul City that are the formal embodiment of intellectual direction of mosque typology as the substance of Islamic doctrine in doing the praying duty. 


\begin{tabular}{llll} 
Al-Rafidain Engineering & Vol.14 & No.3 & 2006 \\
\hline
\end{tabular}

roton:1

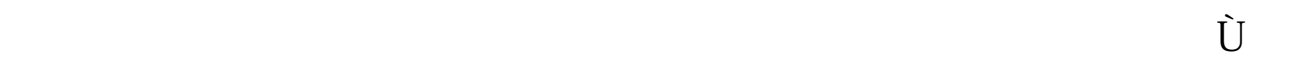

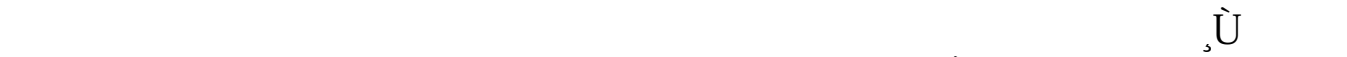

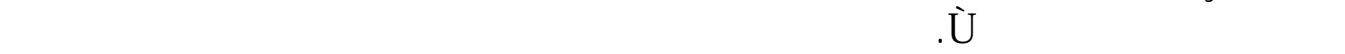

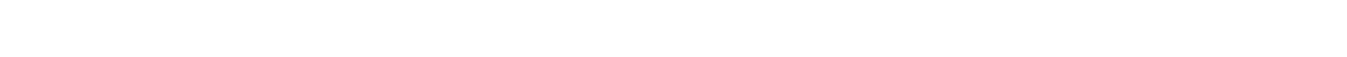

(12 ů

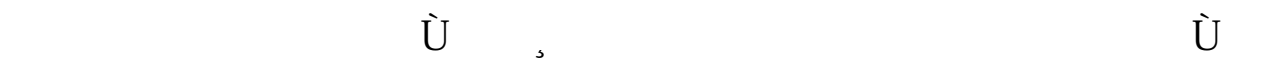

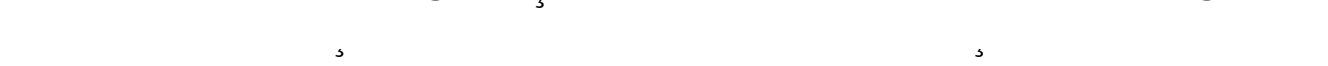

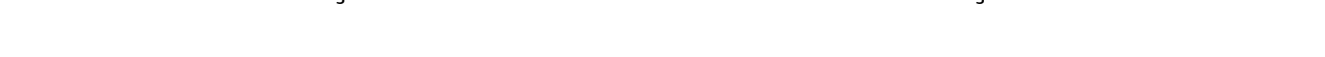

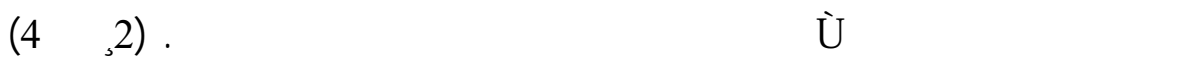

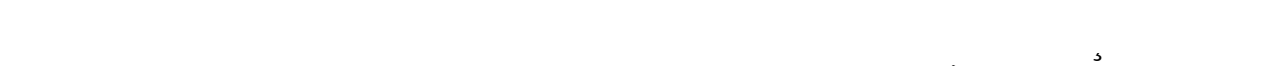

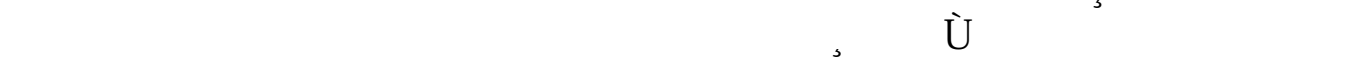

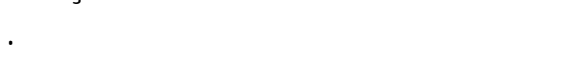

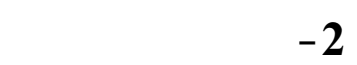

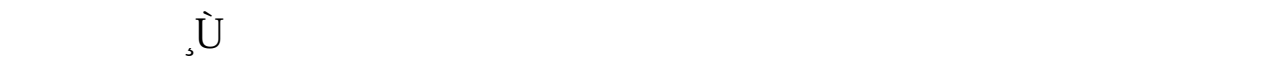
FṬ̂ GE

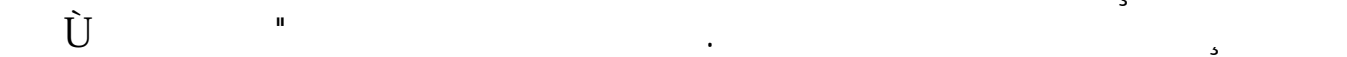

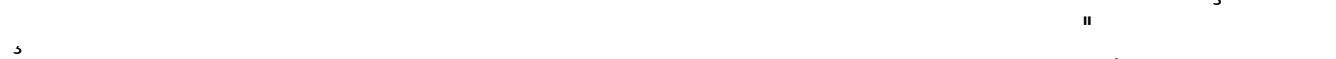

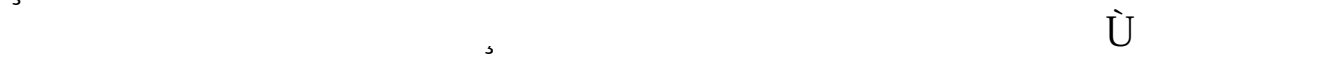

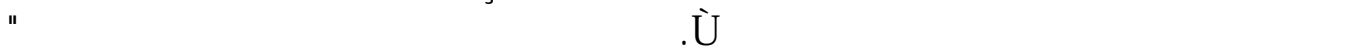

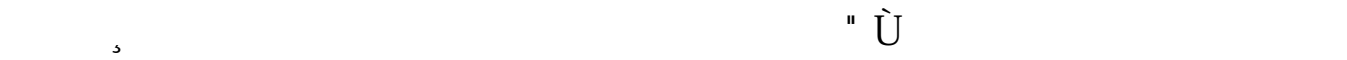

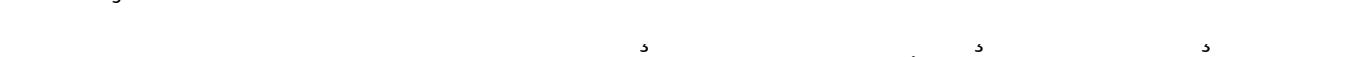

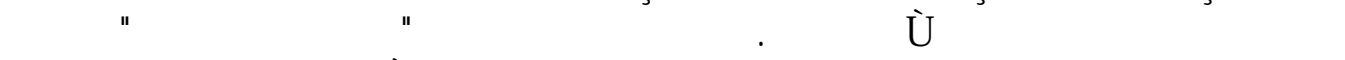

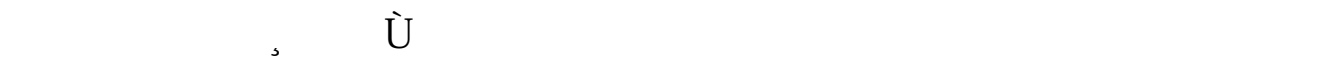

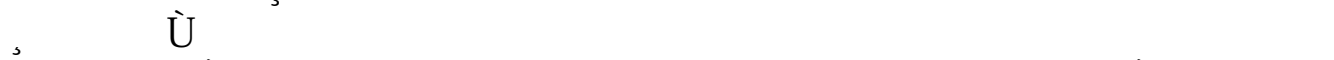

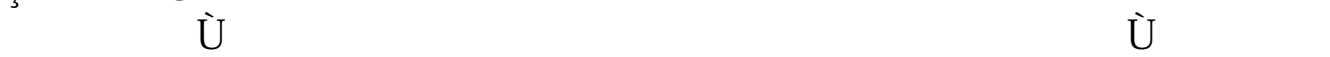

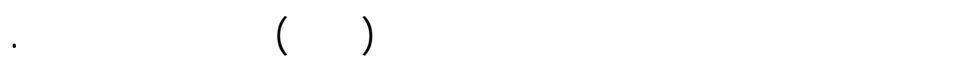

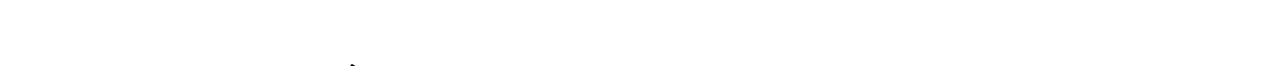

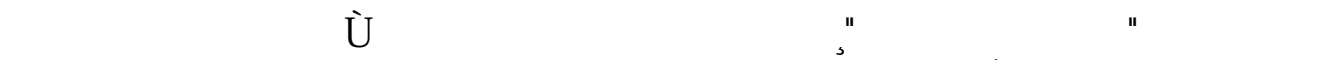

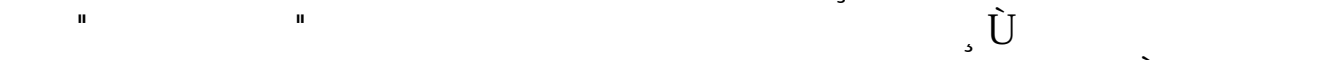

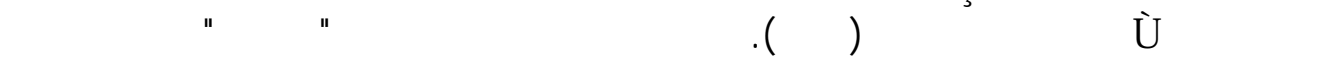

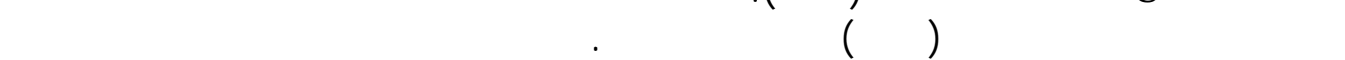

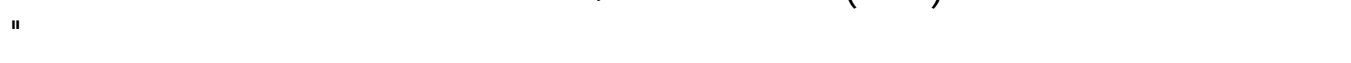

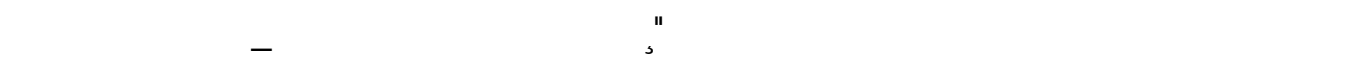

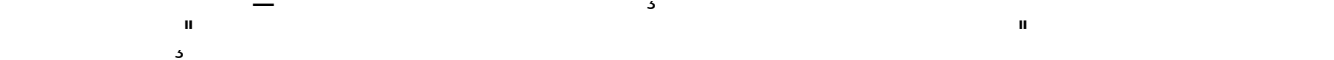

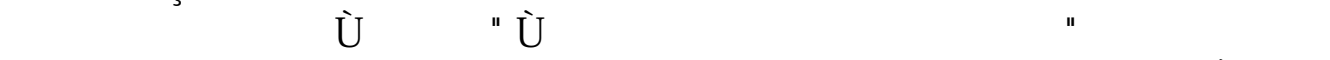

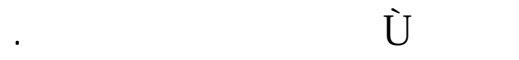




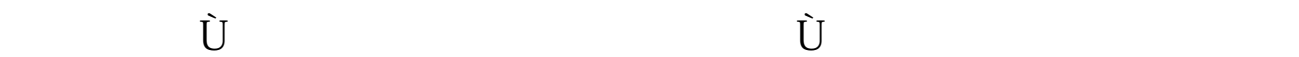

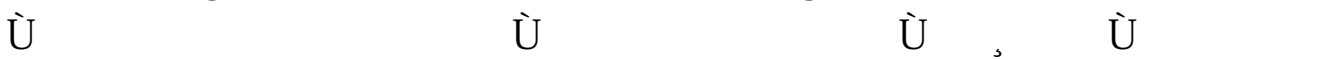

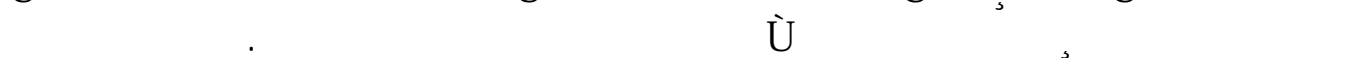

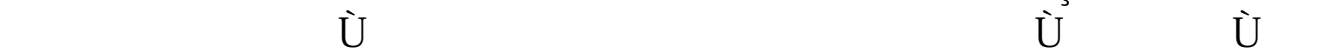

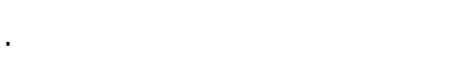

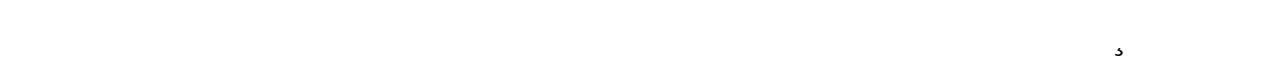

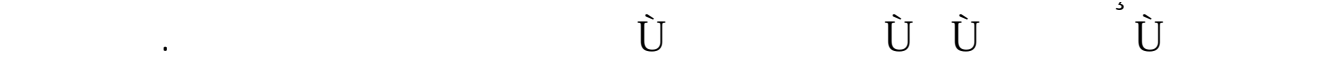

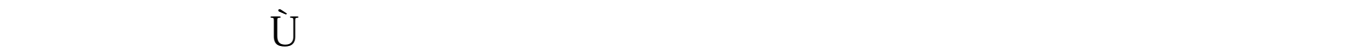

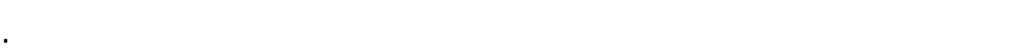

\section{Vิ}

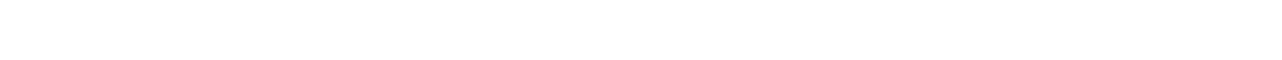

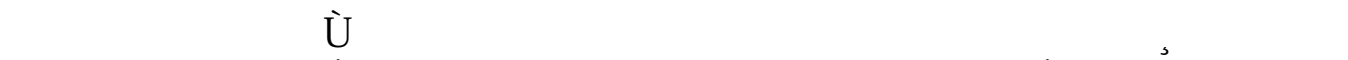

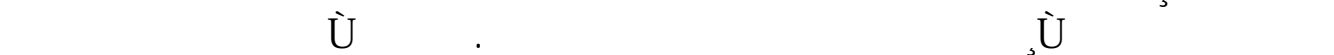

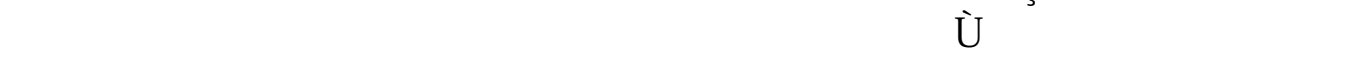

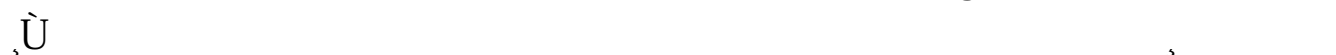

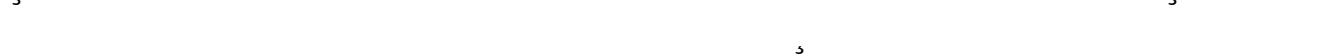

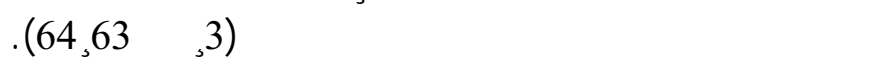

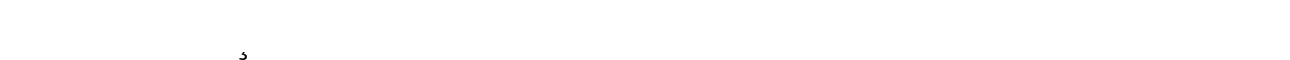

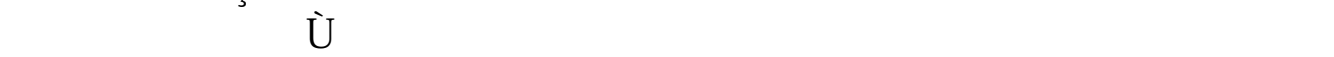

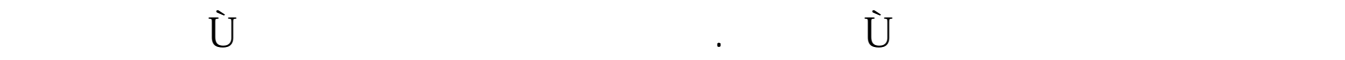

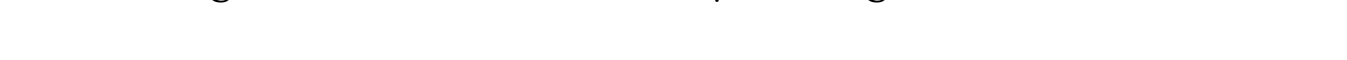

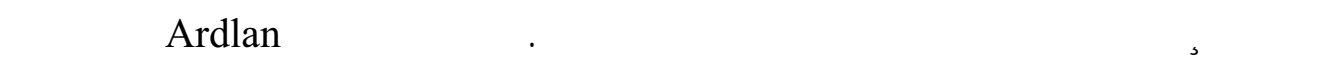

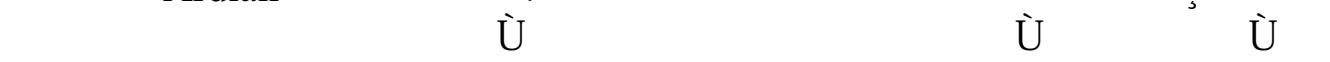

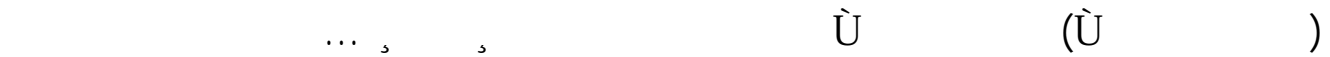

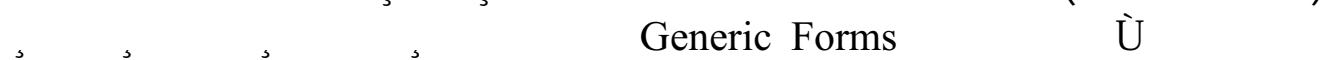

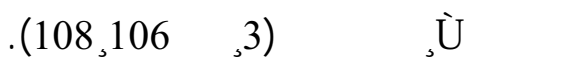

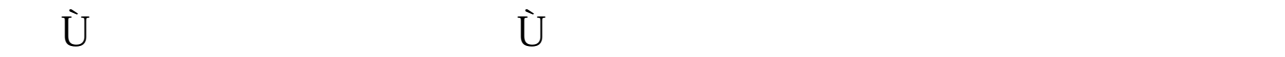

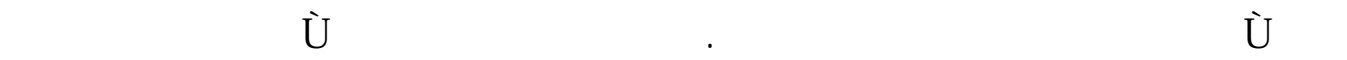

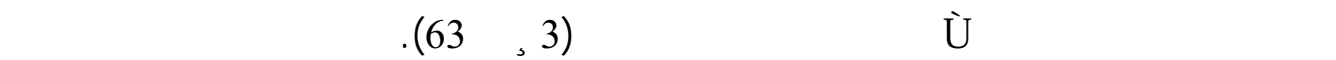

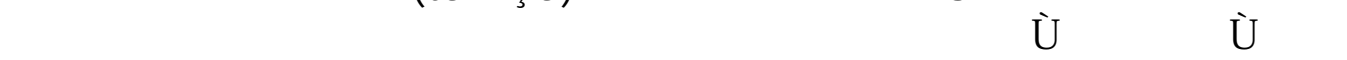

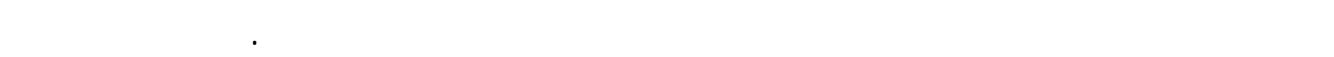

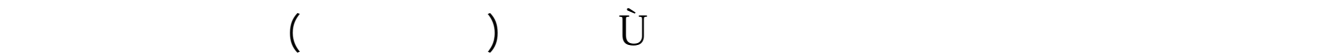

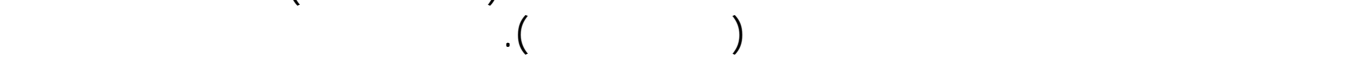

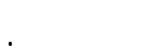

\section{Vิ}

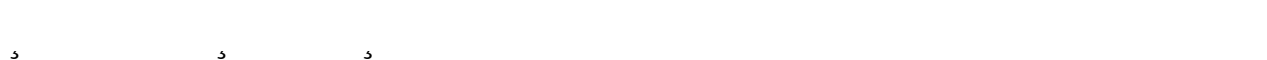

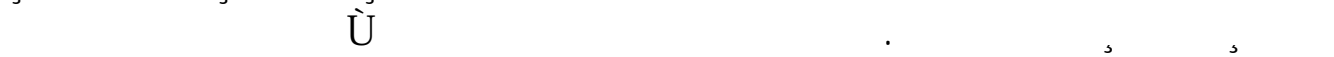

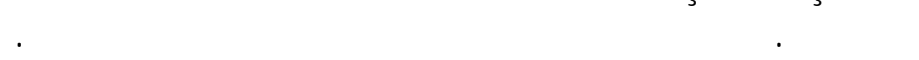

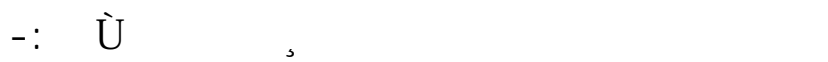




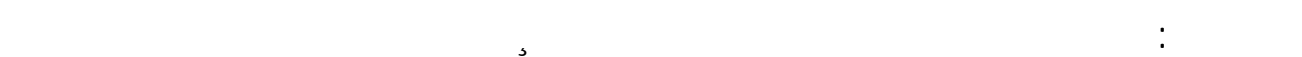
. (389ů

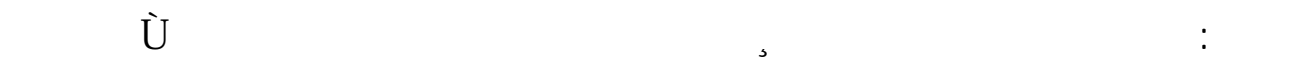

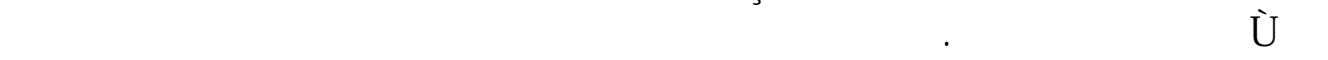

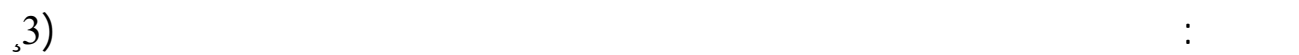
(250ů

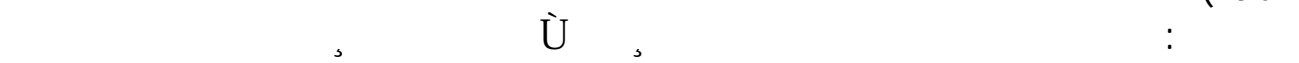

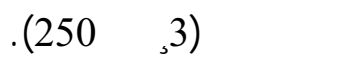

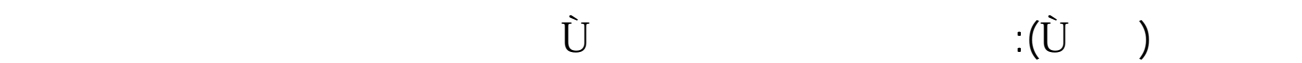

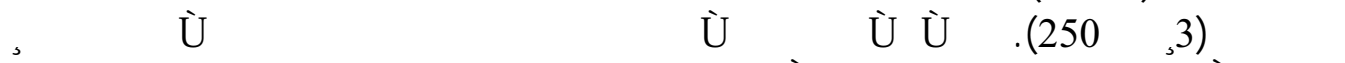

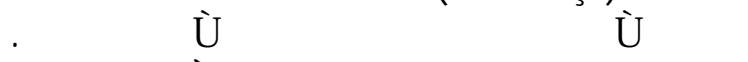

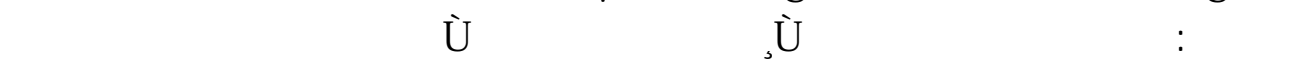

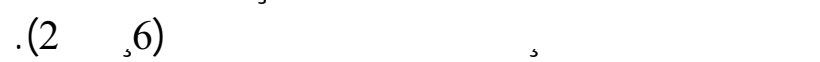

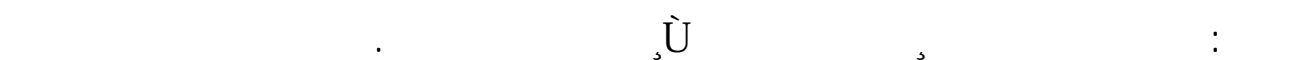

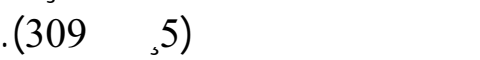

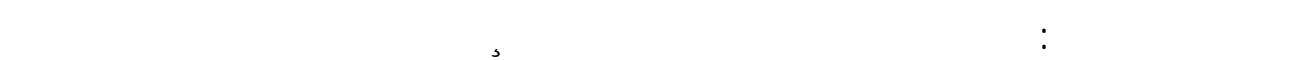

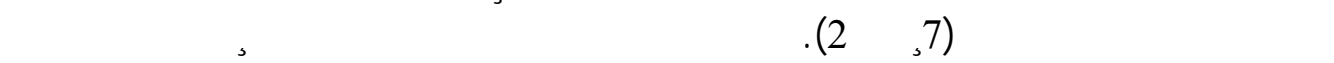

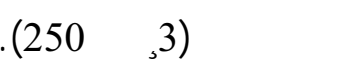

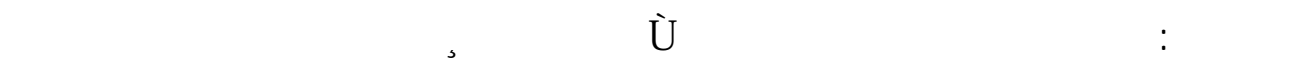

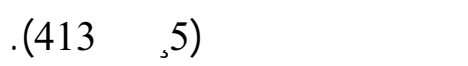

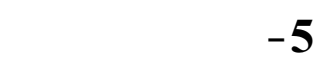

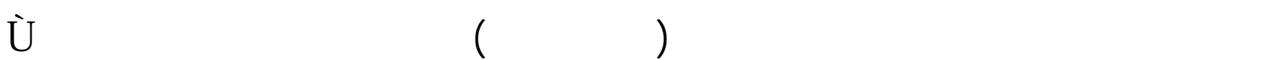

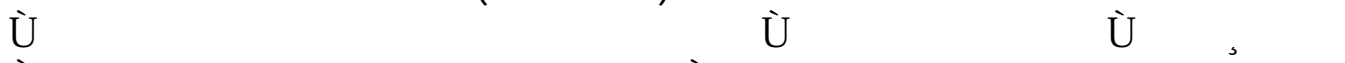

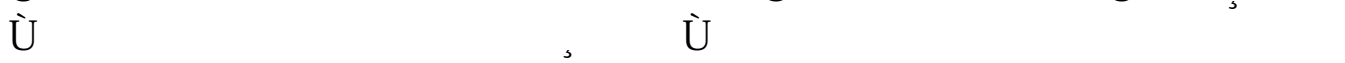

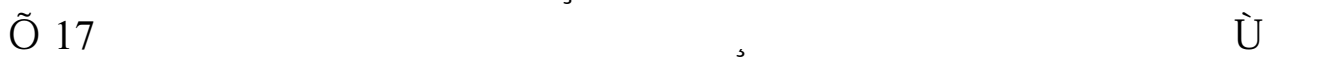

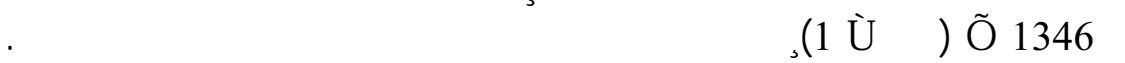

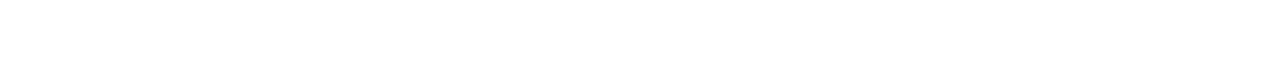

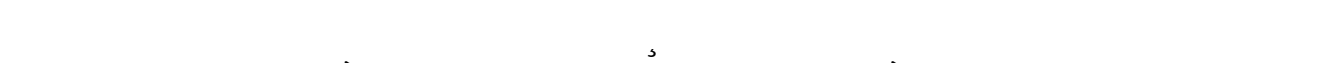

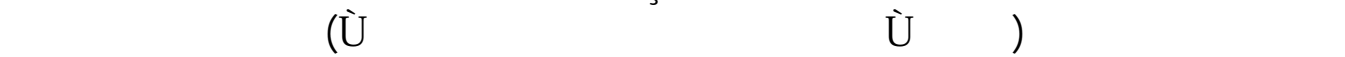

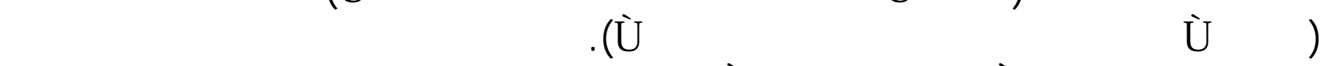

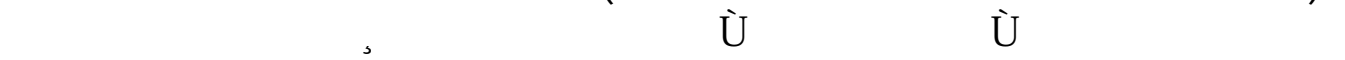

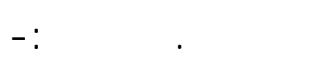

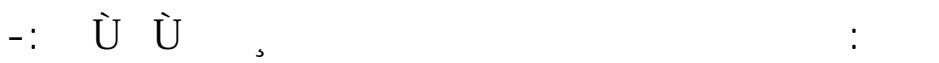

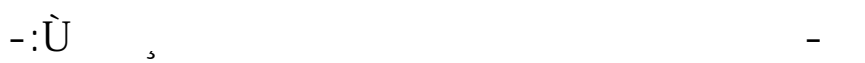
FD̋ d姆: 'nthé丶 $2-00$

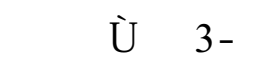




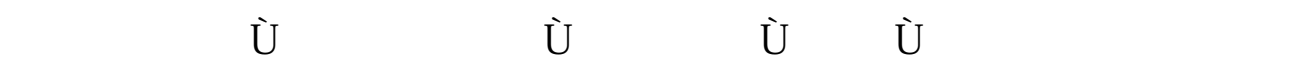

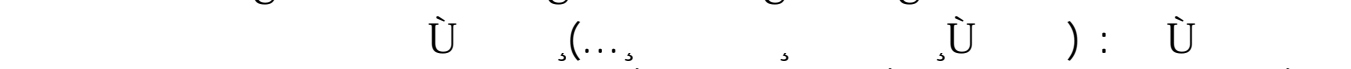

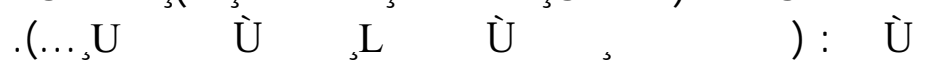

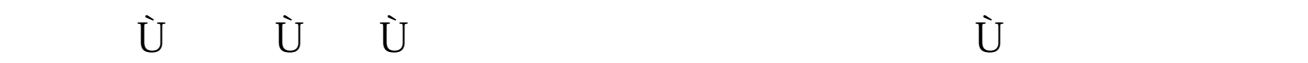

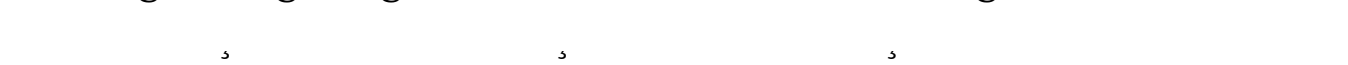

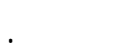

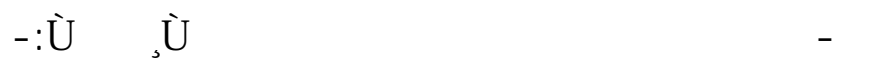

(řšũ

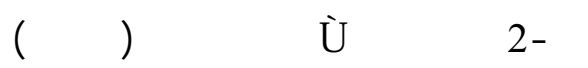

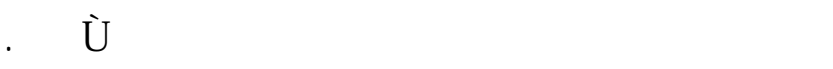

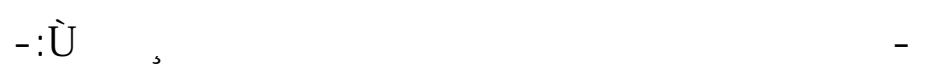

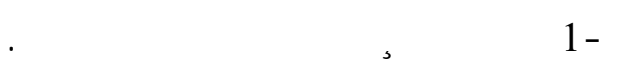

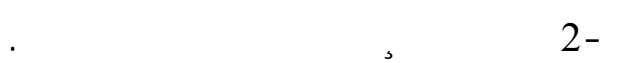

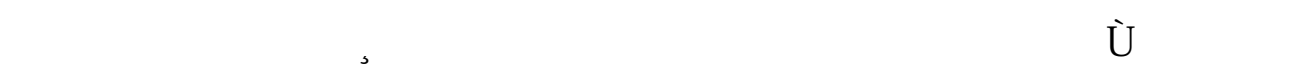

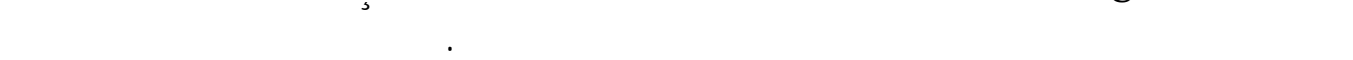

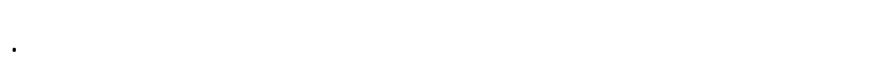

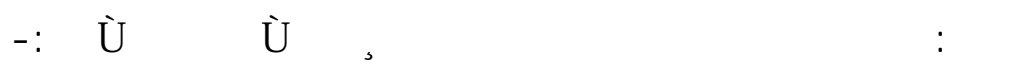

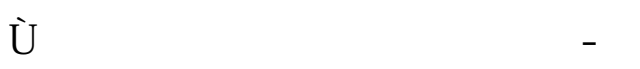

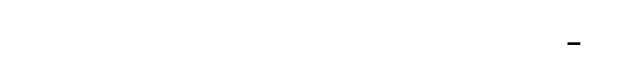

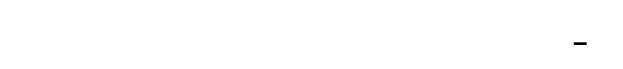

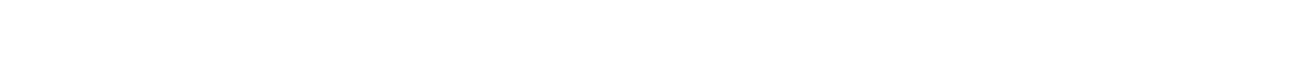

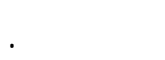

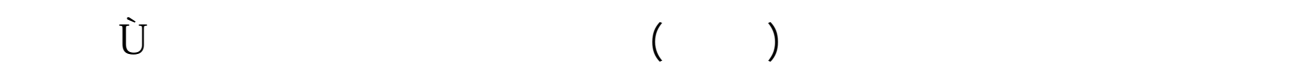

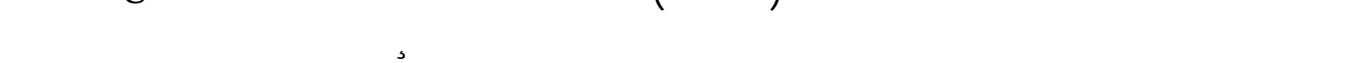

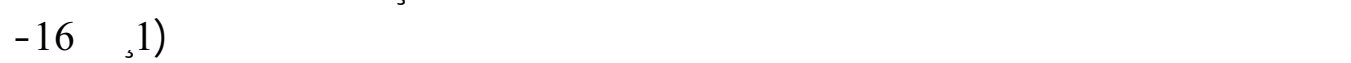

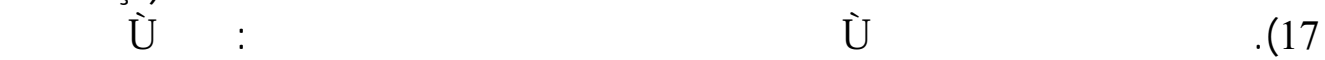

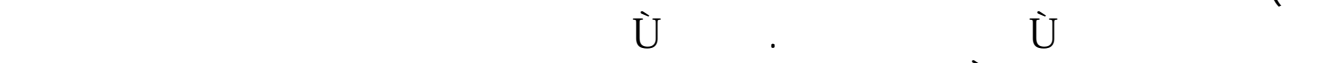

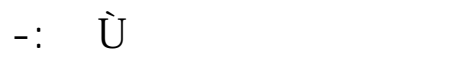

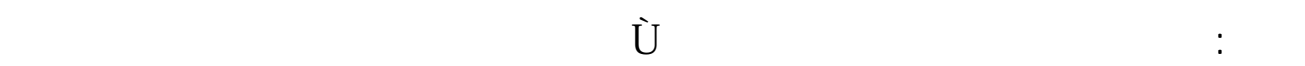

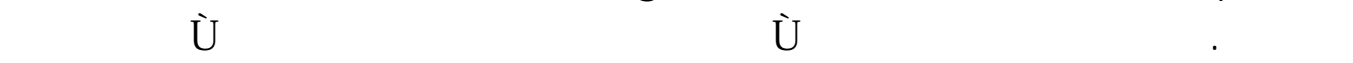
.FD́ dŔ

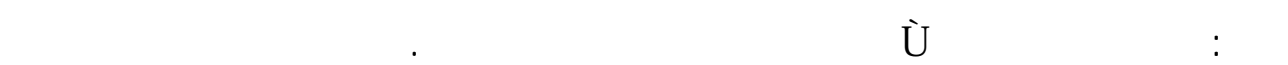

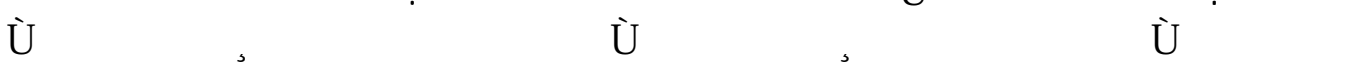

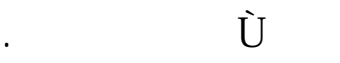


$\begin{array}{llll}\text { Al-Rafidain Engineering } & \text { Vol.14 } & \text { No.3 } & 2006\end{array}$

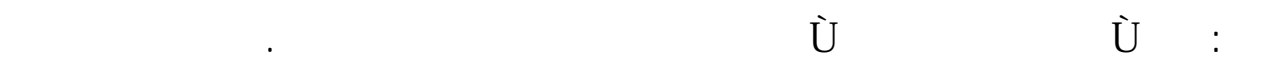

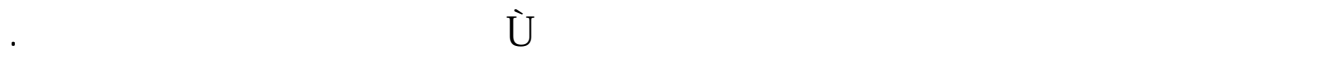

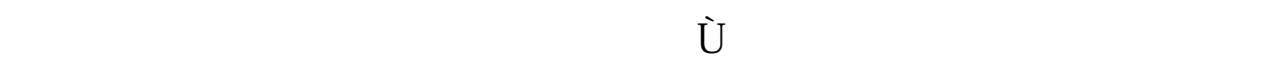

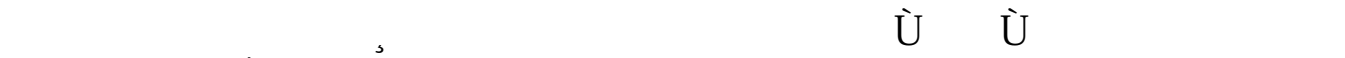

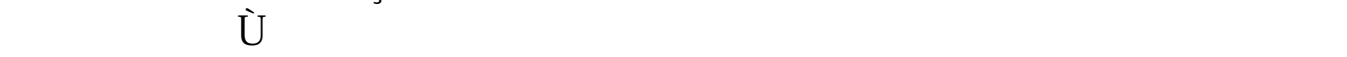

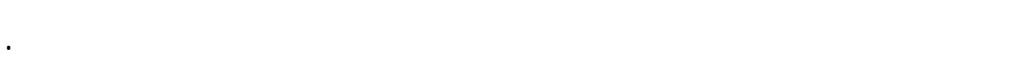

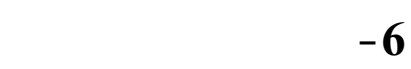

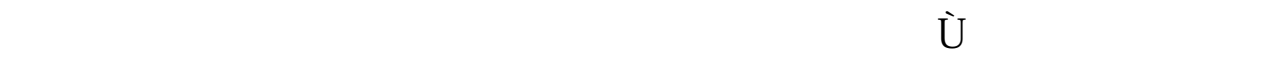

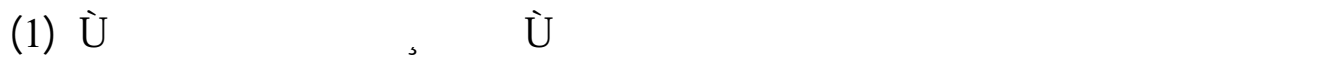

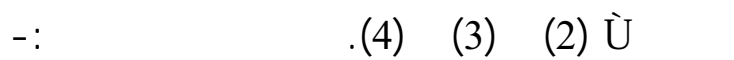

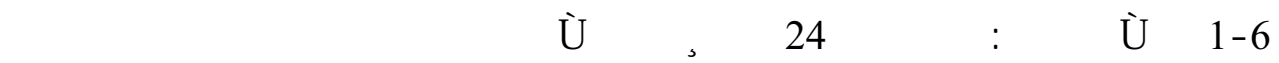

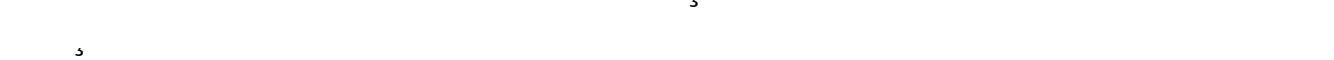

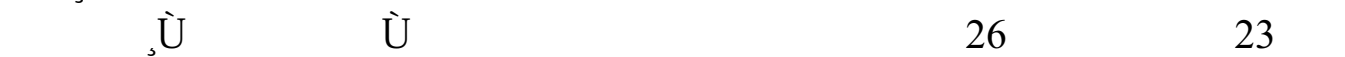

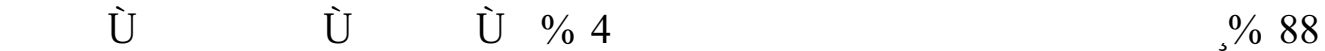

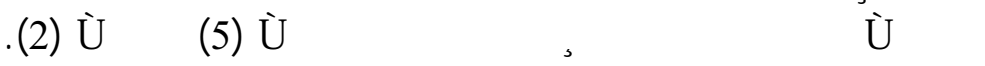

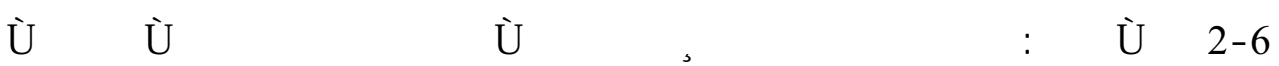

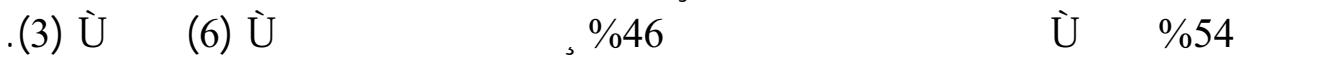

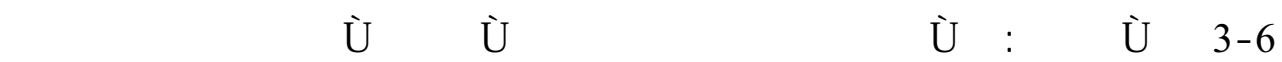

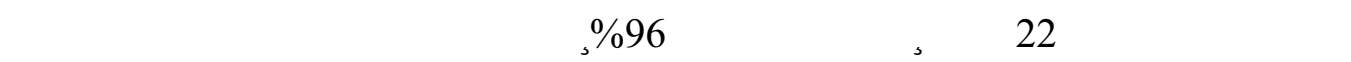

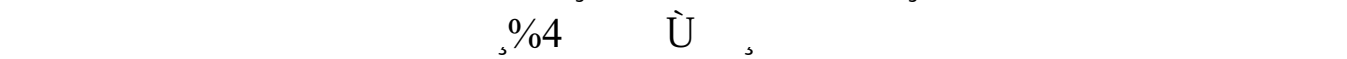

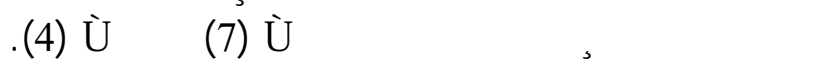

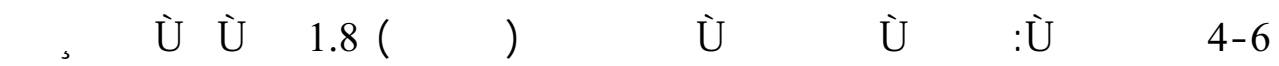
. Ýर́' ¿

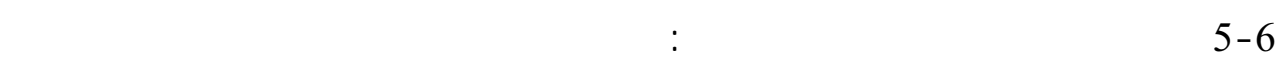

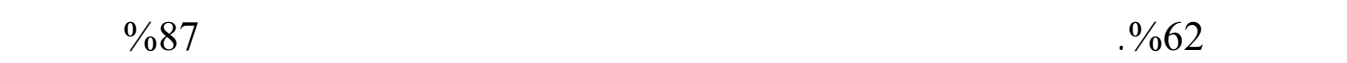

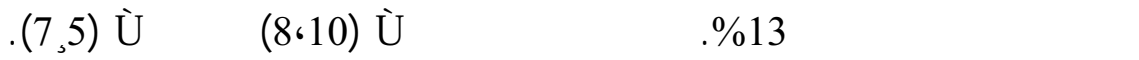

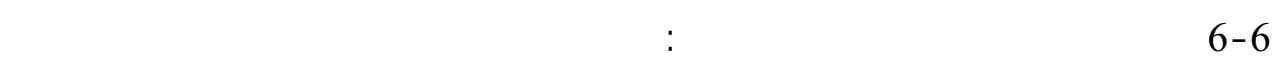

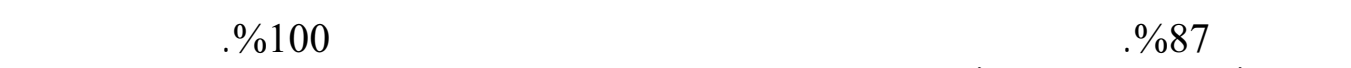

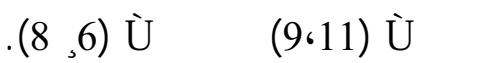

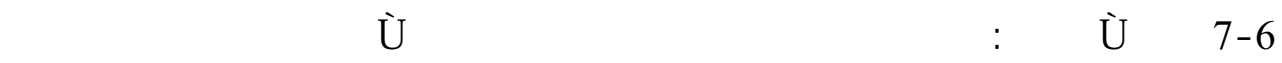

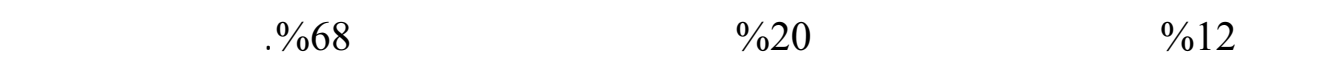

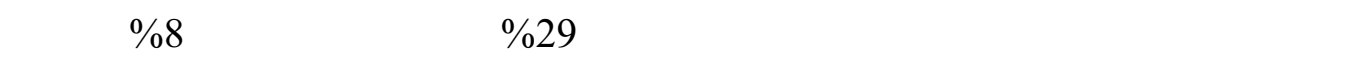

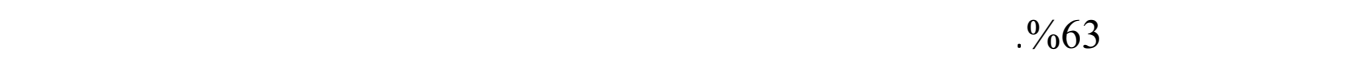

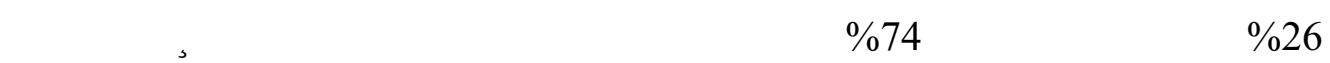

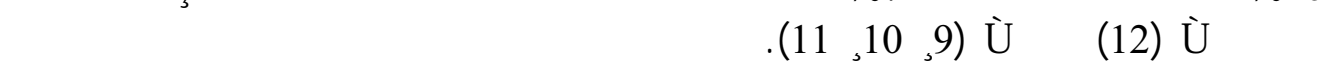




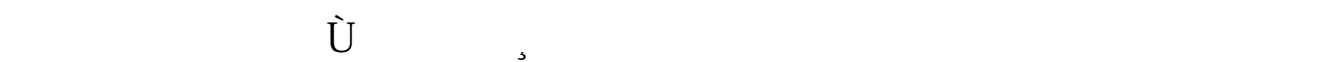

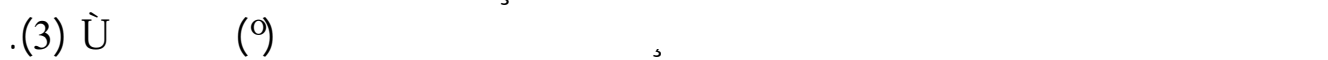

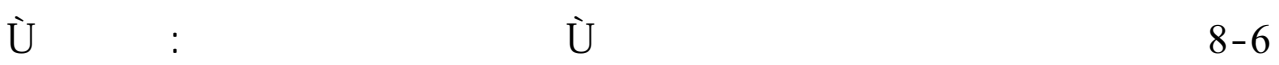

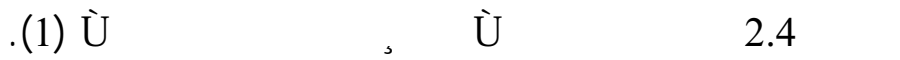

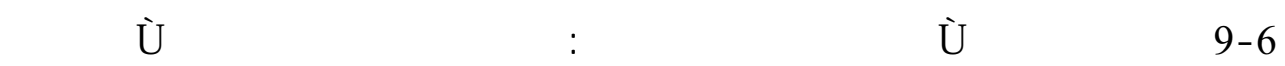

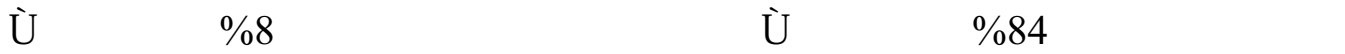

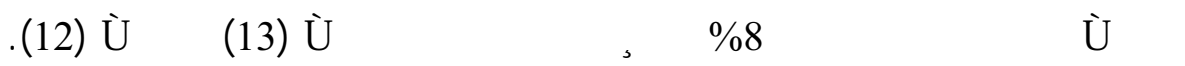

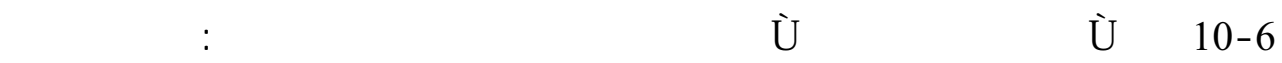

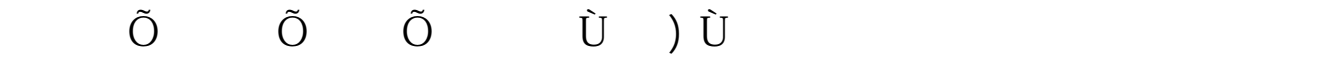

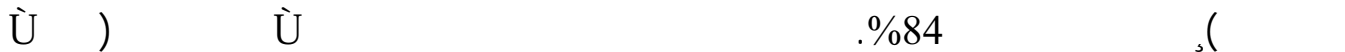

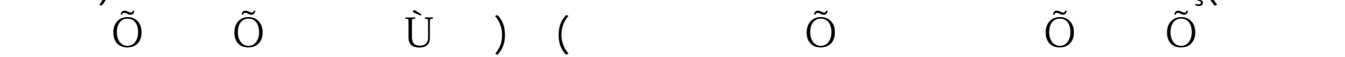

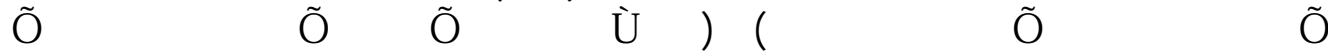

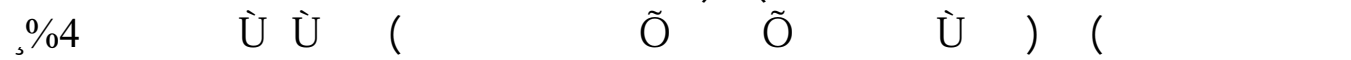

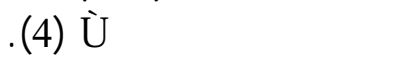

\section{Řgữug7}

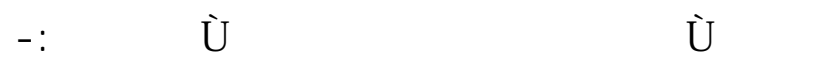

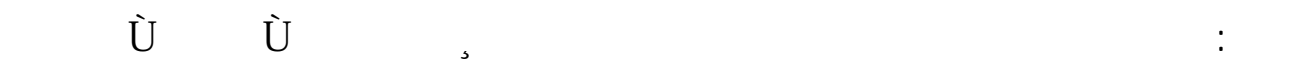

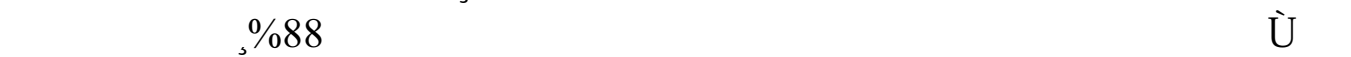

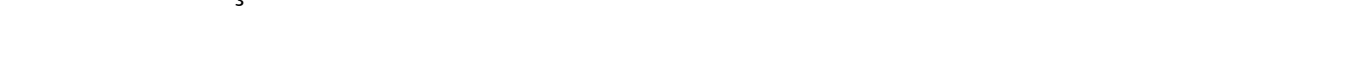

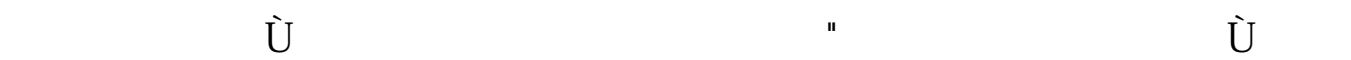

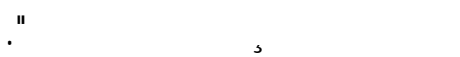

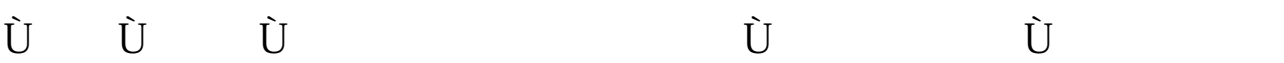

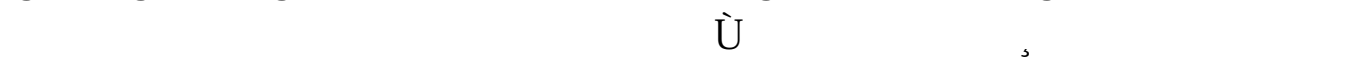

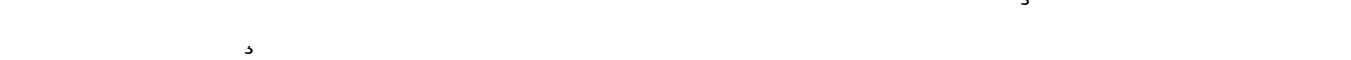

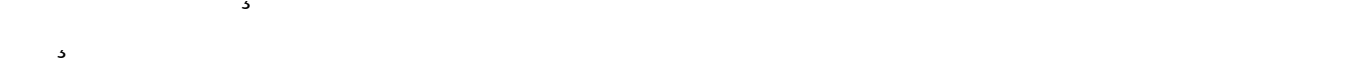

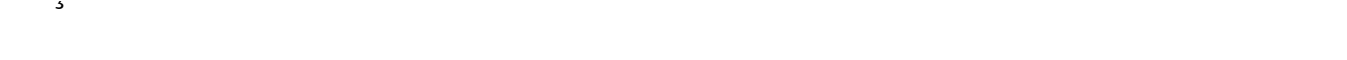

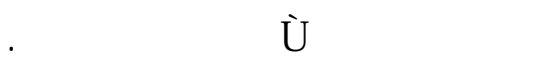

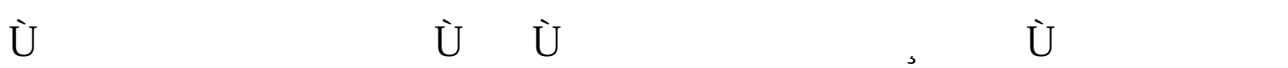

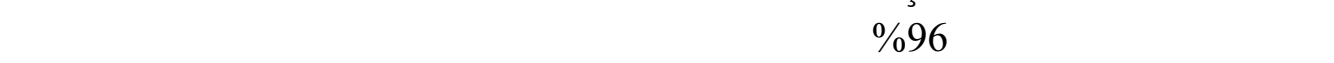

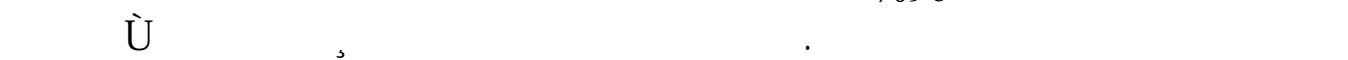

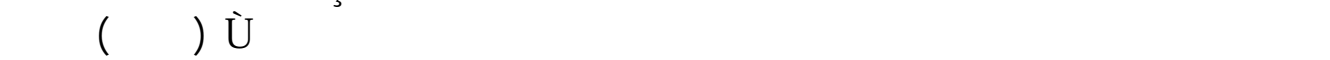

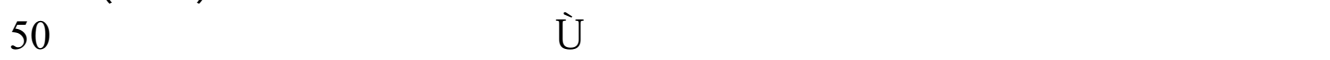

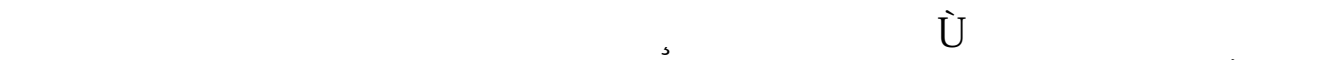

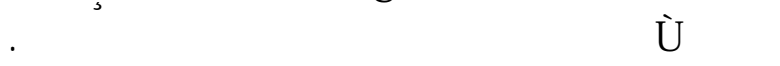

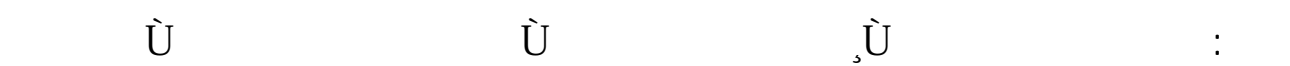

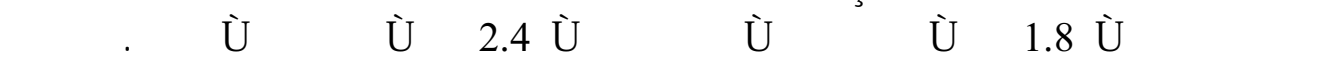

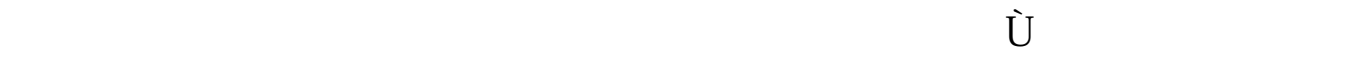




$\begin{array}{llll}\text { Al-Rafidain Engineering } & \text { Vol.14 } & \text { No.3 } & 2006\end{array}$

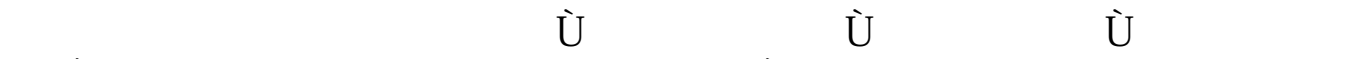

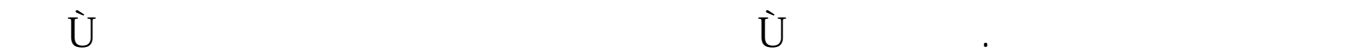

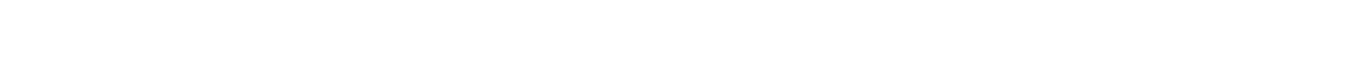

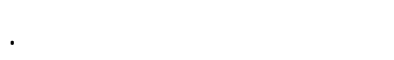

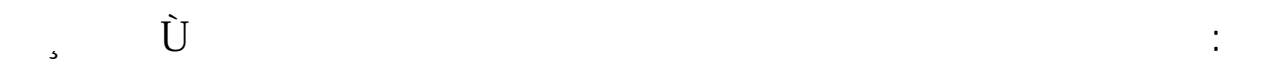

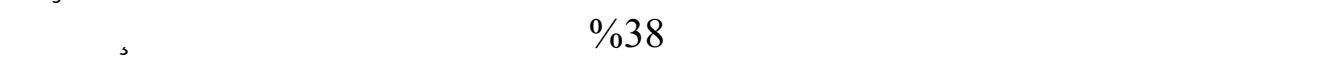

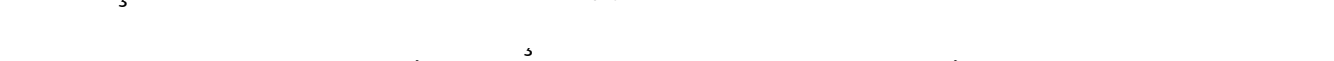

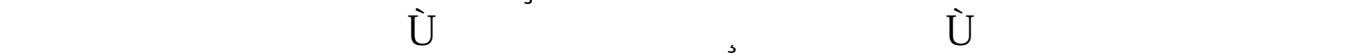

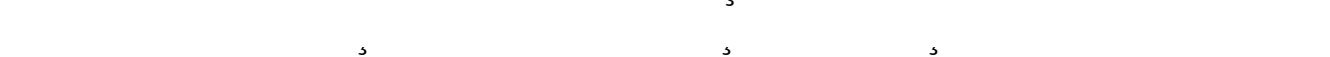

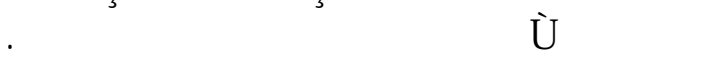

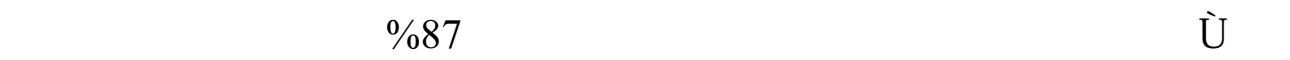

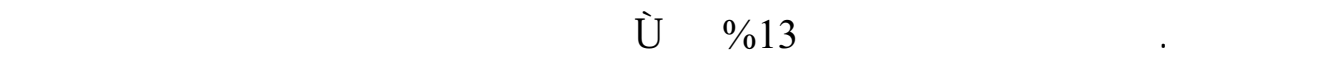

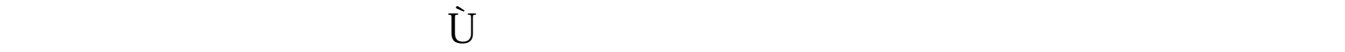

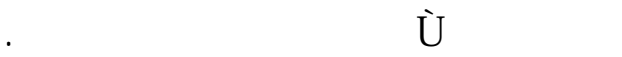

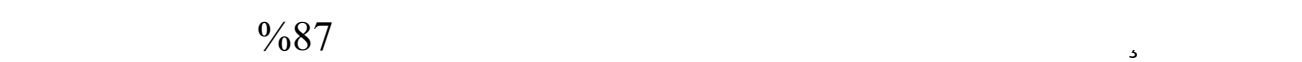

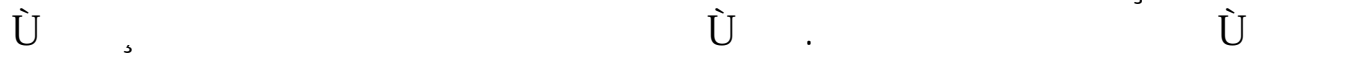

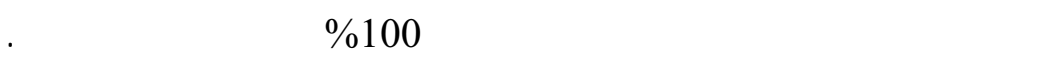

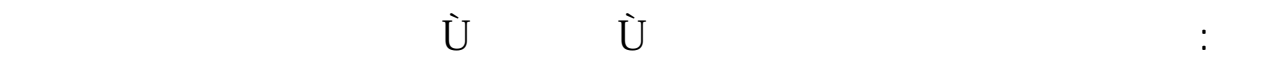

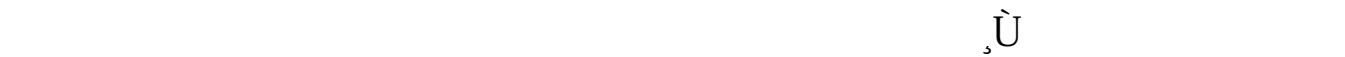

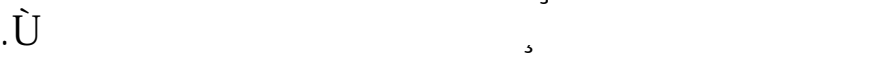

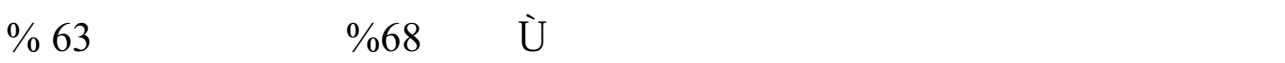

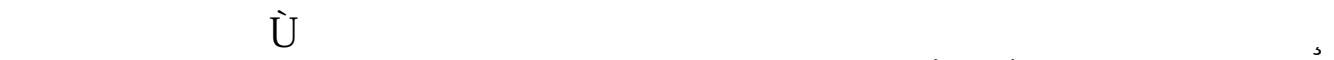

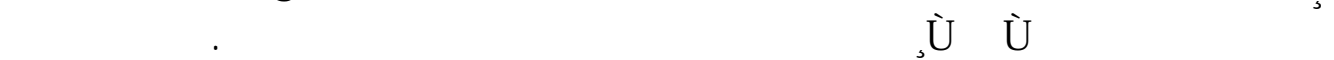

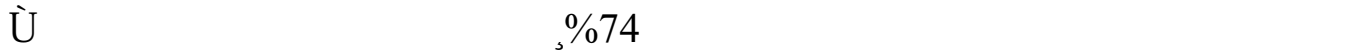

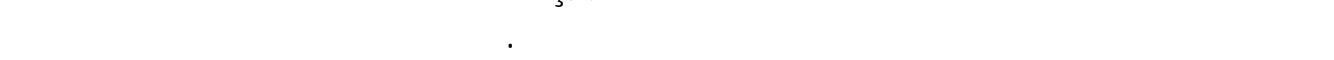

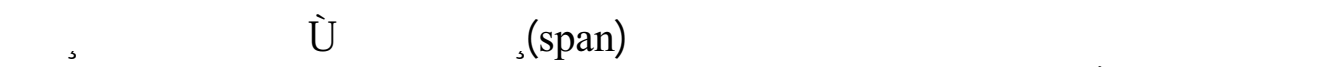

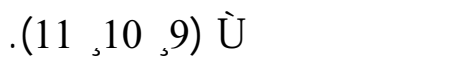

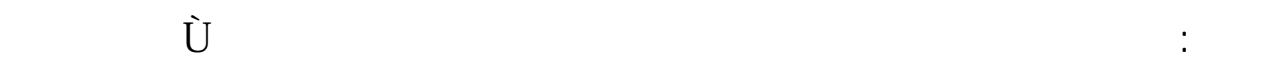

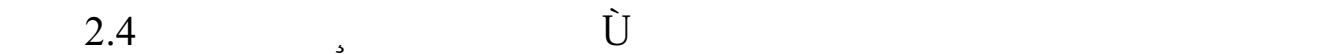
Ũ

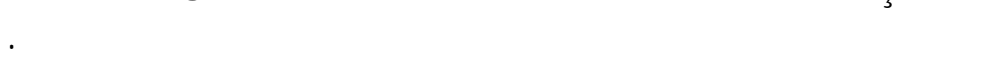

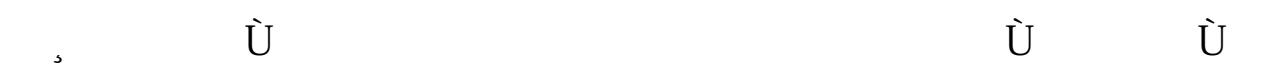

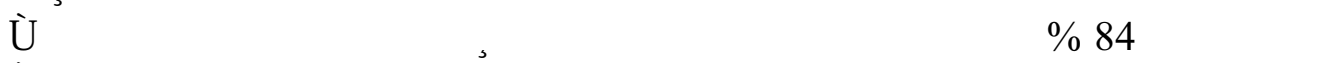

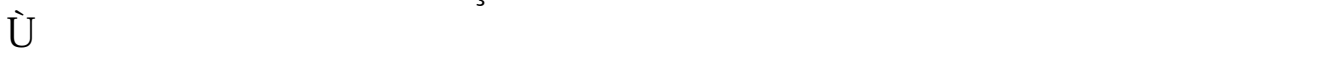

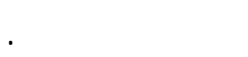

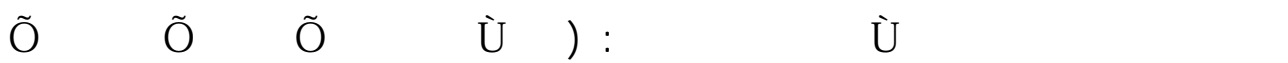

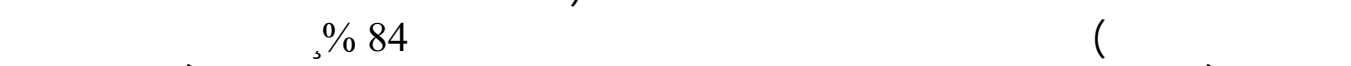

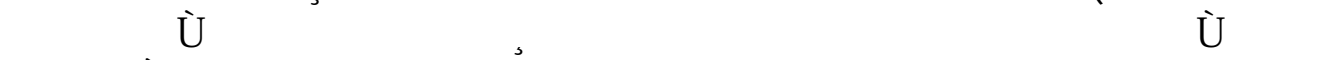

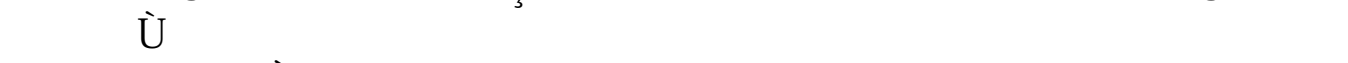

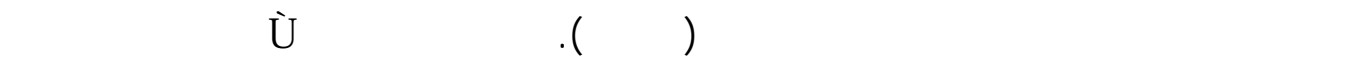




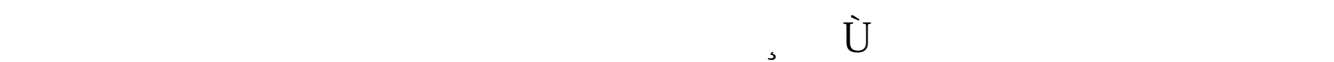
.řs

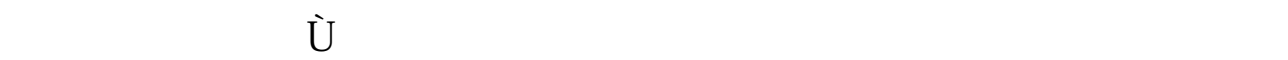

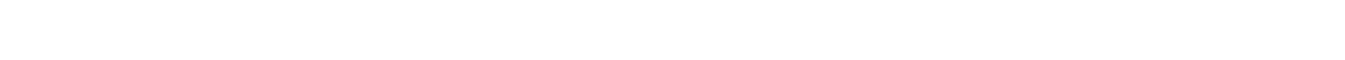

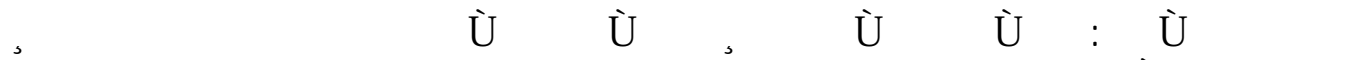

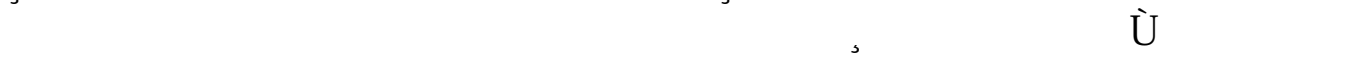

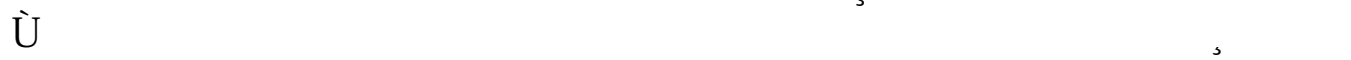

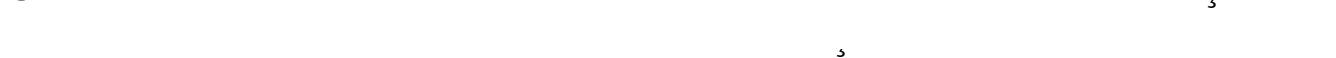

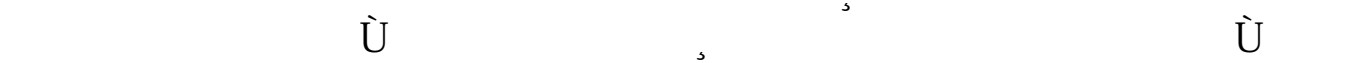

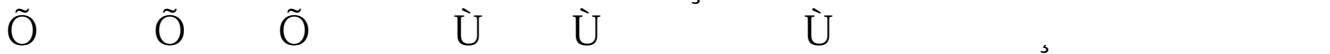

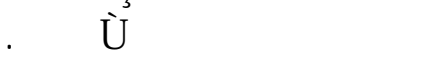

\section{R̆g̊̊gikE8}

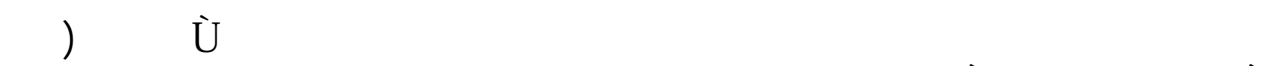

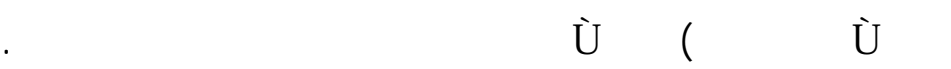

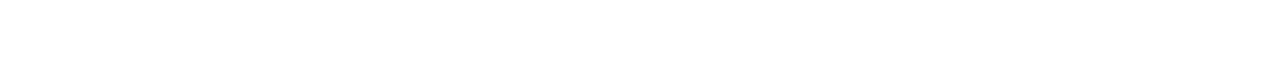

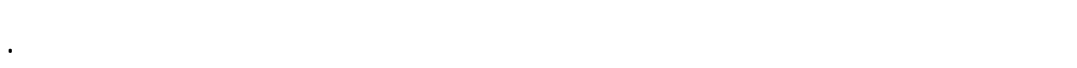

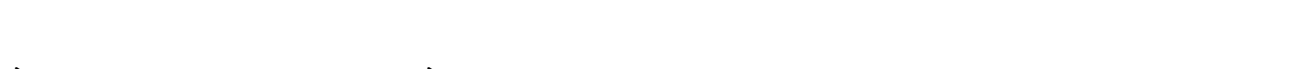

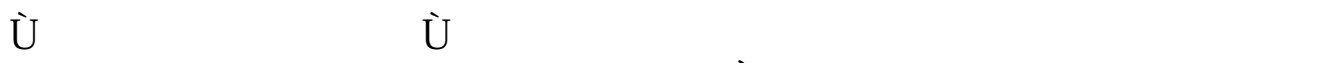

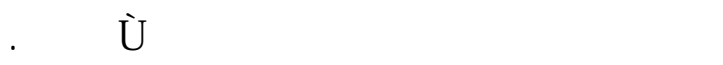

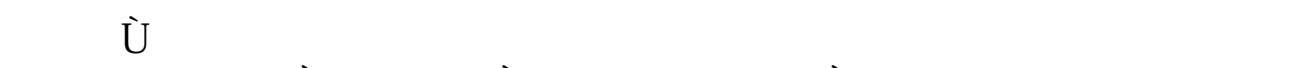

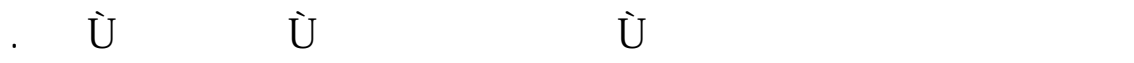

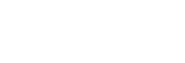

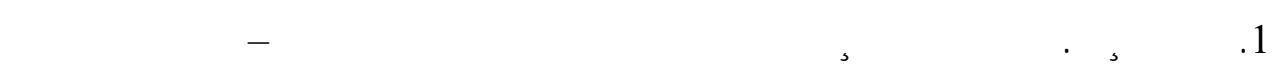

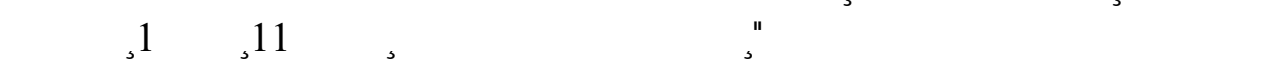

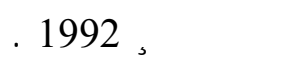

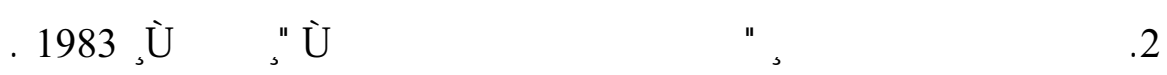

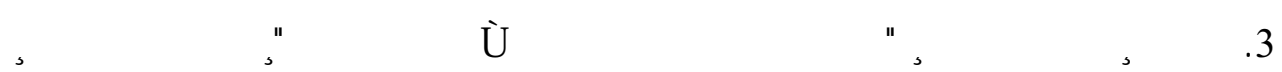

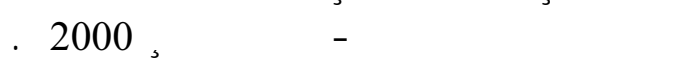

4. Tesar, Paul, “ The Other Side Of Types ”, “ Types and the (Im) Possibilities of Convention, CALA, U.S.A, 1991.

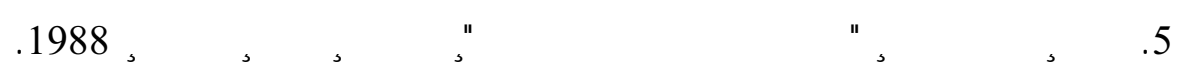

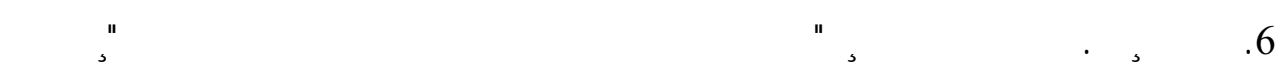

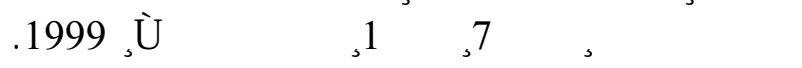




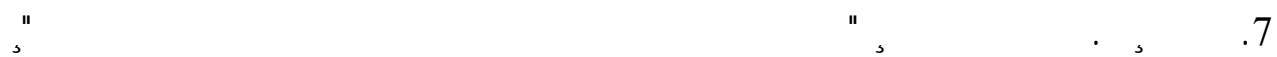

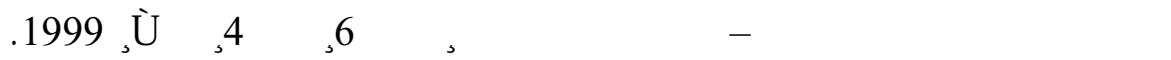

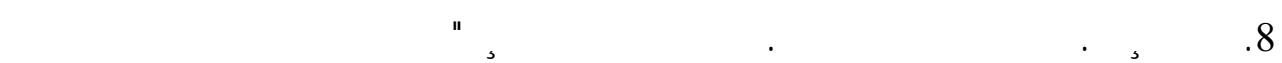

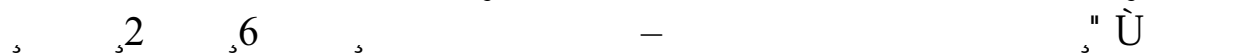
.1999

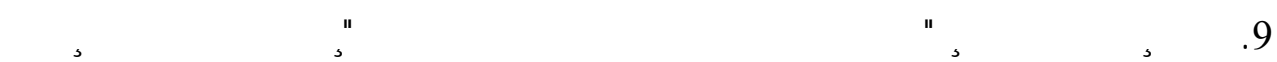

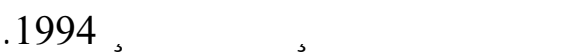

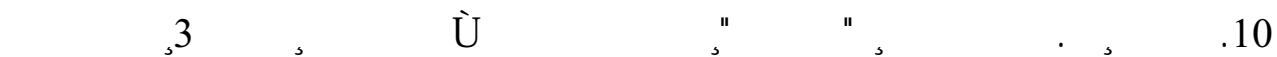

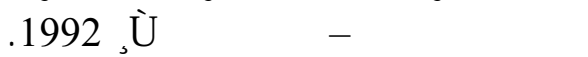

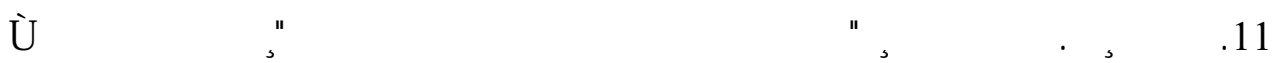

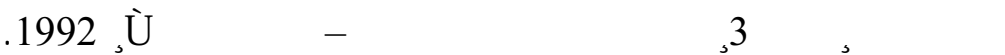

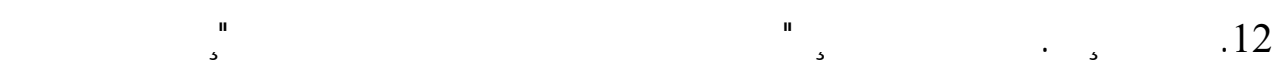

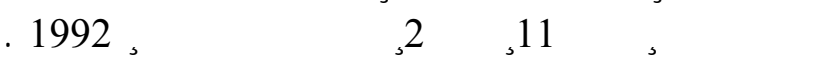

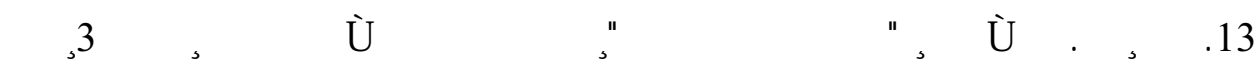

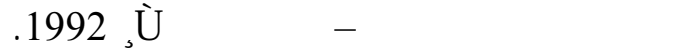

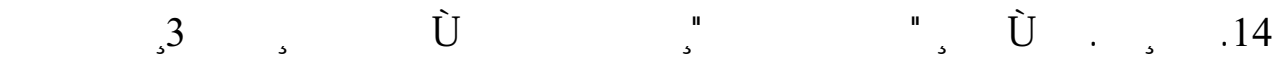

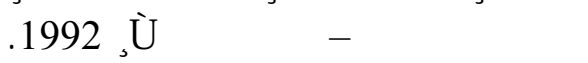

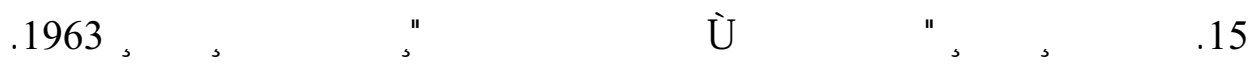


الملحق

\begin{tabular}{|c|c|c|c|c|c|}
\hline 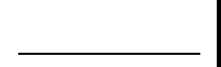 & Vigorie & Vispiñ & 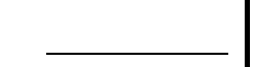 & VISTRE & 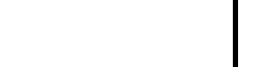 \\
\hline b $755 / 0$ a 196 & 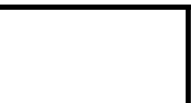 & dét:T13 & b638/o a 7 & 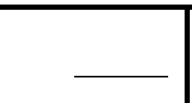 & Egðの=1 \\
\hline b $764 / 0$ a 178 & $\begin{array}{l}\text { tfứrE } \\
\text { Fšřz }\end{array}$ & 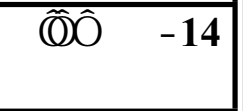 & $\begin{array}{c}1170 / 0 \text { あ65 } \\
\text { b }\end{array}$ & 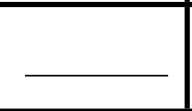 & EtgdiE2 \\
\hline b $766 /=$ a 189 & If̂: :E & IfYi:iE15 & $\begin{array}{c}\text { 1365/o क72 } \\
\text { b }\end{array}$ & Ŕgứríće & Etagsit3 \\
\hline b $779 / 0$ a 193 & 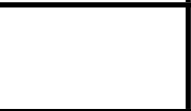 & 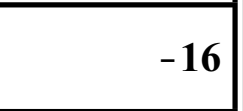 & $\begin{array}{c}\text { 1393/o đ797 } \\
\text { b }\end{array}$ & Fídinćé & 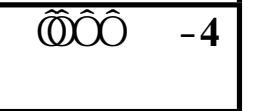 \\
\hline b $780 / 0$ a 194 & coijone & $\begin{array}{r}\text { も으으 - } 17 \\
\varepsilon t e d\end{array}$ & $\begin{array}{c}\text { 1562/o Z70 } \\
\text { b }\end{array}$ & 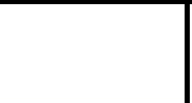 & पftốर5 \\
\hline b 794/으 a 209 & $\begin{array}{l}\text { Visg } \\
\text { tfus }\end{array}$ & ty̆gs - 18 & $\begin{array}{c}\text { /o a1060 } \\
10650\end{array}$ & žgū $€ \overline{\mathbf{U}}$ & FŞfgSirit6 \\
\hline b $798 / 0$ a 213 & 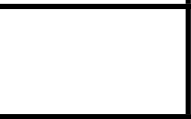 & |fक्षिए19 & $\begin{array}{c}\text { /o a1080 } \\
10569\end{array}$ & 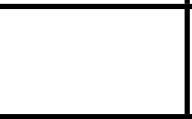 & 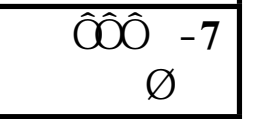 \\
\hline b 804/o a 219 & 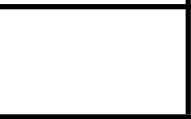 & dgăLE20 & $\begin{array}{c}\text { /o a1081 } \\
10670\end{array}$ & 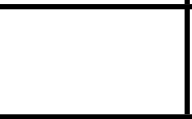 & $\begin{array}{r}\text { tรuัoo o KIE8 } \\
\text { tว̌ร้ว }\end{array}$ \\
\hline b814/으 a 230 & ŔgürŔá & $\begin{array}{r}\text { Reeoo ŕ- } 21 \\
\text { Ŕgúri }\end{array}$ & $\begin{array}{c}\text { /o a1093 } \\
11682\end{array}$ & žgل̄ $€ \overline{\mathbf{U}}$ & Łăr Ŕũcŷ - 9 \\
\hline b $868 / 0$ a 285 & EgE:G & 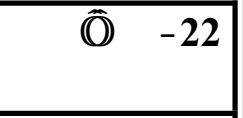 & $\begin{array}{c}\text { /o a } 093 \\
10682 \\
\end{array}$ & tşūo'śáa & 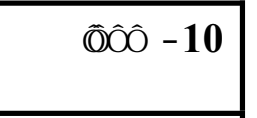 \\
\hline b880/o a 298 & Coijone & 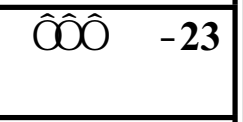 & $\begin{array}{c}\text { /o a105 } \\
10693 \\
\end{array}$ & Egdant & も䏒国11 \\
\hline b927/o a 346 & $\begin{array}{l}\text { uteds } \\
\text { F"̌sdiE }\end{array}$ & 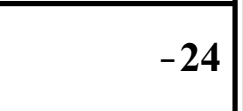 & $\begin{array}{c}\text { /o a } 114 \\
\text { b703 }\end{array}$ & $\operatorname{cog} \mathrm{SnE}$ & Řgன́ன̆12 \\
\hline
\end{tabular}

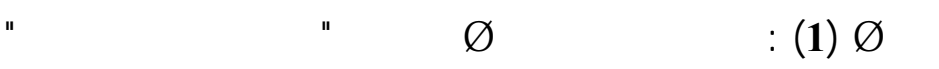

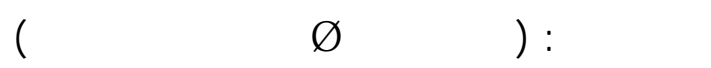




$\begin{array}{llll}\text { Al-Rafidain Engineering } & \text { Vol.14 } & \text { No.3 } & 2006\end{array}$

\begin{tabular}{|c|c|c|c|c|c|c|c|c|c|}
\hline 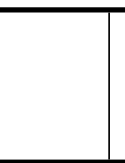 & $\begin{array}{c}t^{\prime} \hat{\prime} \hat{W} \\
\text { Cón } \\
\mathbf{R}\end{array}$ & $\frac{\hat{\text { Vibs }}}{\text { rctort }}$ & $\begin{array}{c}t^{\prime} \hat{w} \\
\mathrm{fb} \\
\mathrm{C} \\
\end{array}$ & $\begin{array}{c}t^{\prime}{ }^{\prime} \hat{w} \\
. \mathbf{b} \\
. t^{\prime}\end{array}$ & $\begin{array}{c}\mathbf{t}^{\prime} \hat{w} \\
. \mathbf{b} \\
. \mathbf{T}\end{array}$ & $\begin{array}{l}3 /{ }^{3} \\
z ̌ g=t E\end{array}$ & 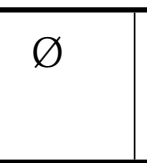 & 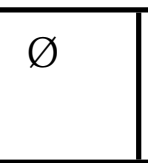 & 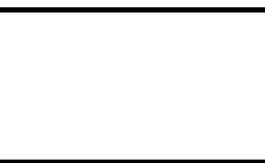 \\
\hline 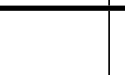 & 1 & 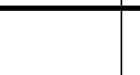 & 1 & 1 & 2 & 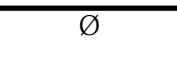 & 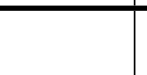 & 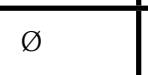 & Eghn:1 \\
\hline 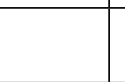 & 1 & 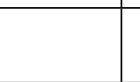 & 1 & 3 & 3 & 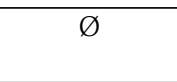 & 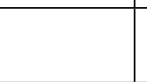 & סטיז'ואנ & EtgdiI2 \\
\hline 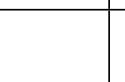 & 1 & $\begin{array}{l}\text { tş̧ğk } \\
\text { rodo }\end{array}$ & & 1 & 2 & 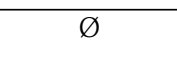 & $\begin{array}{l}\text { tý́ Fǘta } \\
\text { Fügé }\end{array}$ & 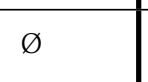 & Etagsin3 \\
\hline 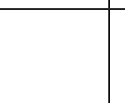 & 2 & 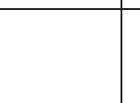 & 1 & 3 & 3 & 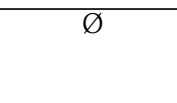 & 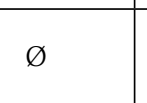 & 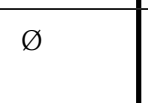 & ũ fSES Fíd TF \\
\hline 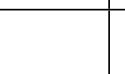 & 1 & 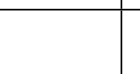 & 1 & 3 & 2 & 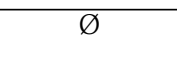 & סี & 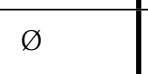 & 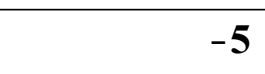 \\
\hline 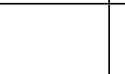 & 1 & 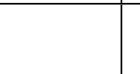 & 1 & 3 & 1 & 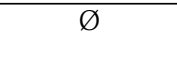 & 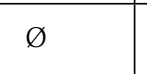 & & 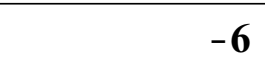 \\
\hline 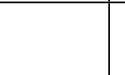 & 1 & 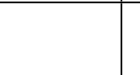 & 1 & 3 & 2 & 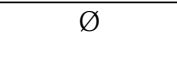 & $\begin{array}{l}\text { ț̇́ Fū'tid } \\
\text { Fügé }\end{array}$ & סריד & 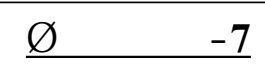 \\
\hline 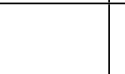 & 1 & $\begin{array}{l}\text { tśğk } \\
\text { rod }\end{array}$ & & 3 & 2 & 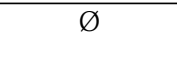 & $\begin{array}{l}\text { ṫŹFǘtíd } \\
\text { Fügé }\end{array}$ & סิ & 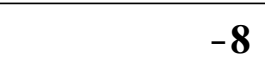 \\
\hline 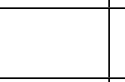 & 1 & 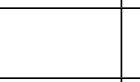 & 1 & 3 & 2 & 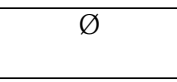 & 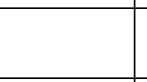 & & t'oūhaد̂̀- 9 \\
\hline 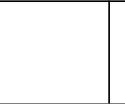 & 1 & $\begin{array}{l}\text { tşgrk } \\
\text { rado }\end{array}$ & & 3 & 2 & 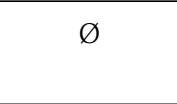 & $\begin{array}{l}\text { týz Fūtáta } \\
\text { Fứge }\end{array}$ & 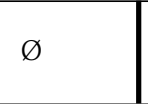 & 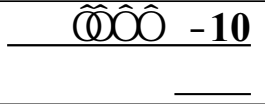 \\
\hline 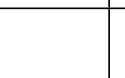 & 1 & $\begin{array}{l}\text { tşsgrk } \\
\text { rad }\end{array}$ & & 1 & 1 & 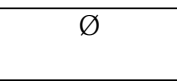 & & 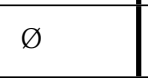 & 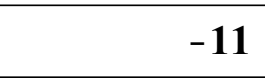 \\
\hline 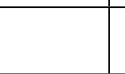 & 1 & 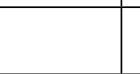 & 1 & 3 & 1 & 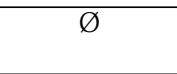 & $\begin{array}{l}\text { EfZFU'tida } \\
\text { Füge }\end{array}$ & 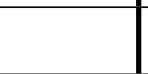 & R̆ǵன் \\
\hline 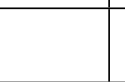 & 1 & $\begin{array}{l}\text { tgos } \\
\text { gaj) }\end{array}$ & 1 & 3 & 2 & 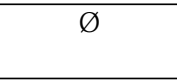 & 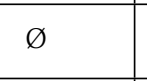 & D" & dÁt:13 \\
\hline $\begin{array}{l}\text { t'śğk } \\
\text { rif }\end{array}$ & & 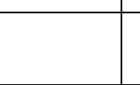 & 1 & 2 & 2 & 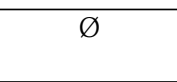 & 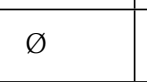 & 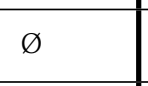 & tat:Treg 4 \\
\hline 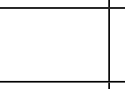 & 1 & $\begin{array}{l}\text { tșğk } \\
\text { rado }\end{array}$ & & 3 & 2 & 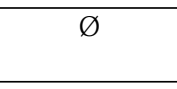 & $\begin{array}{l}\text { tfŹFútída } \\
\text { Fứge }\end{array}$ & 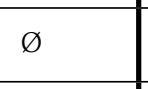 & पீศ्: \\
\hline 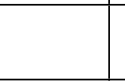 & 1 & 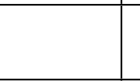 & 1 & 3 & 2 & 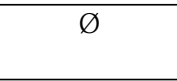 & 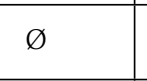 & 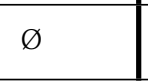 & Fdg Ũ:E16 \\
\hline 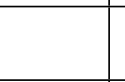 & 1 & $\begin{array}{l}\text { tgas } \\
\text { 295015 }\end{array}$ & 1 & 1 & 2 & 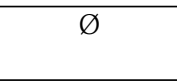 & D̄' & ס̄" & $\varepsilon t^{\prime}(\mathbb{E}\}=E^{\prime}-17$ \\
\hline 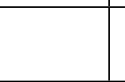 & 1 & $\begin{array}{l}\text { tşgřk } \\
\text { rado }\end{array}$ & & 3 & 2 & 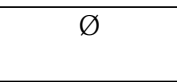 & 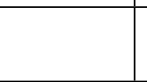 & 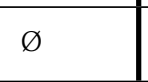 & țŭgs - 18 \\
\hline 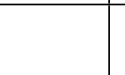 & 1 & 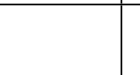 & & 3 & 1 & 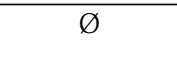 & $\begin{array}{l}\text { țŹFū'td } \\
\text { Fügé }\end{array}$ & 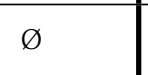 & 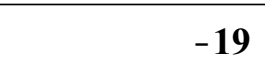 \\
\hline 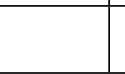 & 1 & $\begin{array}{l}\text { tşgřk } \\
\text { rcti }\end{array}$ & & 1 & 2 & 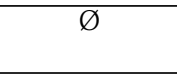 & 3f: & \$D & 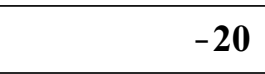 \\
\hline $\begin{array}{l}\text { UEDFż } \\
\text { OADJII }\end{array}$ & 1 & 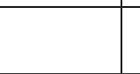 & 1 & 3 & 2 & 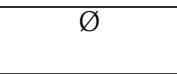 & 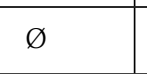 & 3fî̀ & Ŕgứríće 21 \\
\hline $\begin{array}{c}\text { tșgrk } \\
\text { rif }\end{array}$ & & $\begin{array}{c}\text { tşgrak } \\
\text { rad }\end{array}$ & & 1 & 1 & 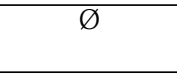 & ס ס & 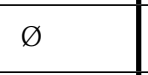 & BŕkC'́n̂́- 22 \\
\hline 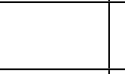 & 1 & 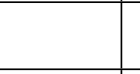 & 1 & 3 & 1 & 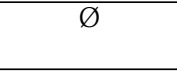 & 3. & 3. & gtī's - 23 \\
\hline 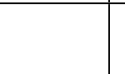 & & $\begin{array}{l}\text { tgap } \\
\text { aqjin }\end{array}$ & 1 & 1 & 1 & & & 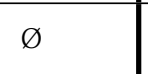 & 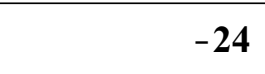 \\
\hline
\end{tabular}

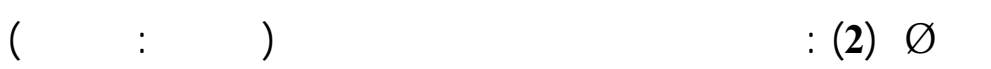

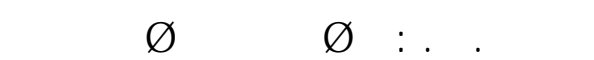

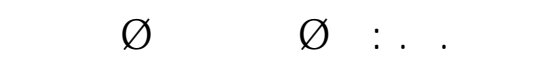




\begin{tabular}{|c|c|c|c|c|c|}
\hline 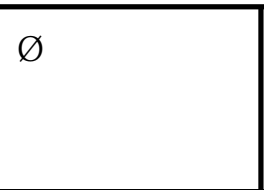 & 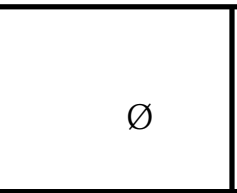 & žgltitônuge & 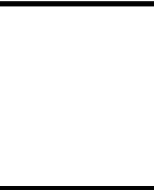 & $\begin{array}{l}\text { tônuge } \\
\text { 3ॅ̆torie }\end{array}$ & V̂forite \\
\hline 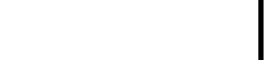 & $3 \square 2$ & rútb & Iftétت்̇ & ทftéciż̊c & Egahr1 \\
\hline 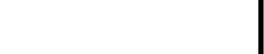 & $4 \square 3 \square 3$ & rúț & றீtédiż̉c & yftétż் & EtgdiE2 \\
\hline 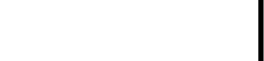 & $3 \square 2$ & rúț & 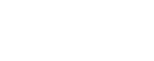 & 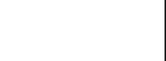 & Etagsis 3 \\
\hline 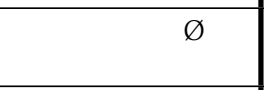 & $\mathbf{2} \square \mathbf{3} \square \mathbf{3}$ & 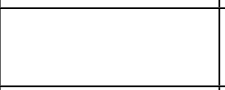 & 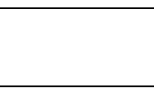 & 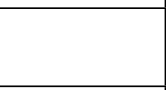 & ũ fSESF FídTI \\
\hline గ1 & $3 \square 2$ & நftétżலீc & 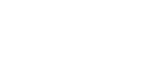 & 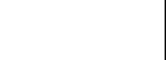 & 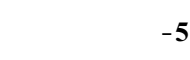 \\
\hline بி & 2 & Iftéciż̇லc & ntécitżலc & rúnt’ & FŞfgshite6 \\
\hline 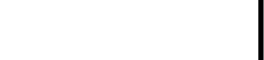 & $2 \square 3$ & 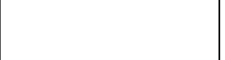 & nftéitżலc & rúnt & 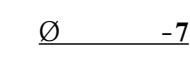 \\
\hline 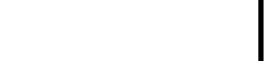 & $2 \square 2$ & rúnţ & rút' & 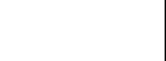 & 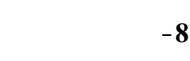 \\
\hline 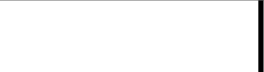 & $3 \square 2$ & ñít & nftétiżீC & ס̄ד̌ & t'gūh \\
\hline 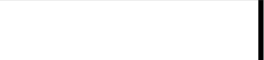 & $3 \square 1$ & rút'̉ & ספד̄ & 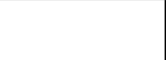 & 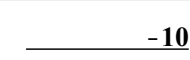 \\
\hline 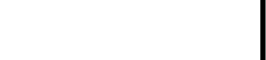 & 1 & ரftédiż & 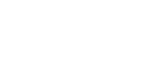 & 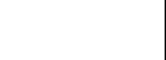 & 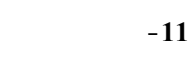 \\
\hline 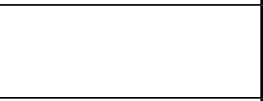 & 2 & rúto & 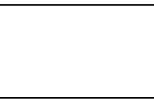 & 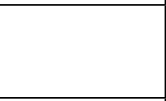 & 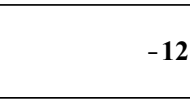 \\
\hline 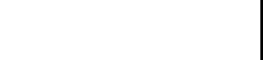 & $3 \square 2$ & rút' & 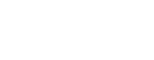 & 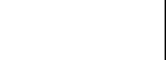 & 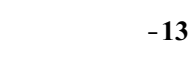 \\
\hline 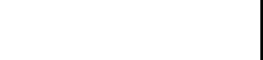 & $3 \square 1$ & rúto & ทftéitżUீc & 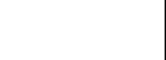 & 七施由 4 \\
\hline 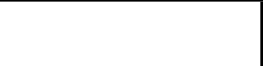 & $3 \square 1$ & rúto & 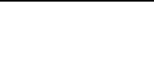 & ספדั & पீf \\
\hline 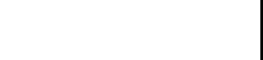 & $3 \square 2$ & rútb & rút' & ríţ & Fog ŨE16 \\
\hline 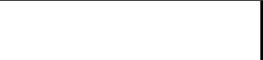 & $2 \square 2$ & ( & 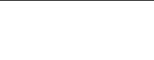 & 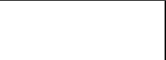 & Et'é):E'- 17 \\
\hline 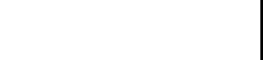 & $2 \square 2$ & rút' & 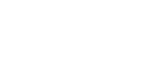 & 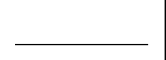 & țǔos - 18 \\
\hline 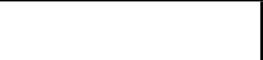 & 2 & rúto & ס̄ד̄ & סَ̄̄ & गfoidre19 \\
\hline 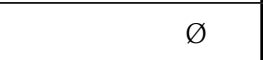 & $2 \square 2$ & ( & ס̄ & 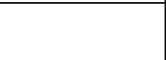 & CGgüLE20 \\
\hline 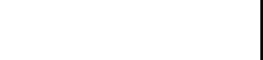 & $2 \square 2$ & $\square$ & 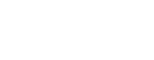 & 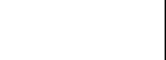 & Ŕgứńće 21 \\
\hline 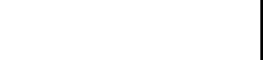 & 2 & $\square$ & 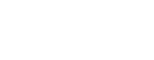 & 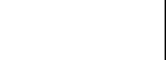 & B'́r K Gî́w- 22 \\
\hline 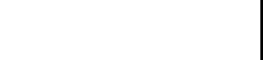 & 2 & rút' & 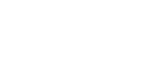 & 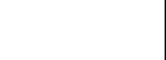 & و 23 \\
\hline 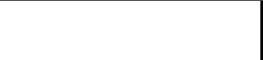 & 1 & žg: t'şg k & Vftéti்பீc & ríto & 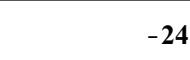 \\
\hline
\end{tabular}

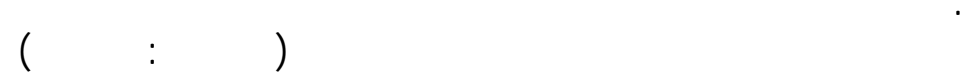




\begin{tabular}{|c|c|}
\hline 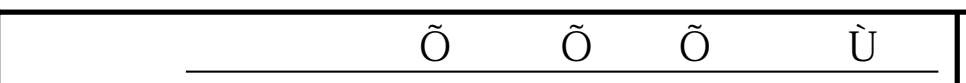 & 正1 \\
\hline 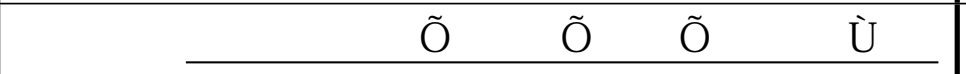 & EtgdiE2 \\
\hline 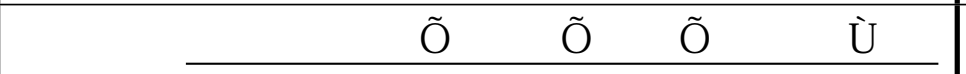 & Etassir 3 \\
\hline 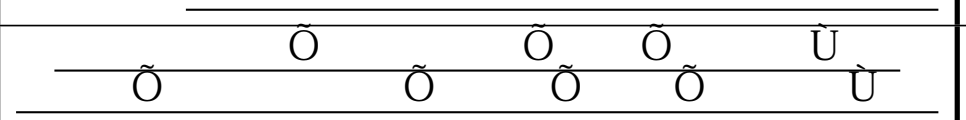 & IF \\
\hline 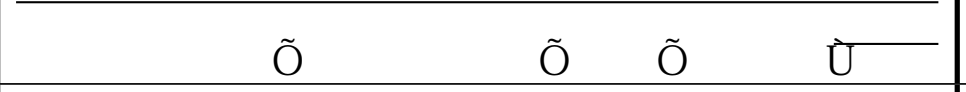 & \\
\hline 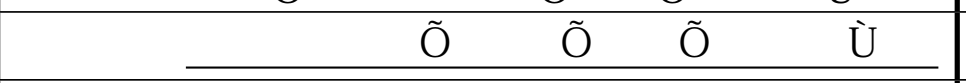 & ins \\
\hline 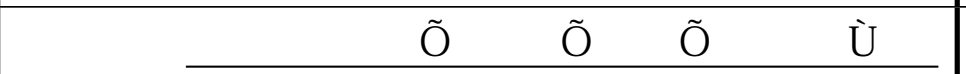 & \\
\hline 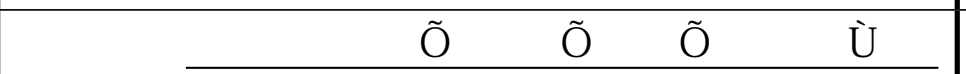 & SE7 \\
\hline d d & 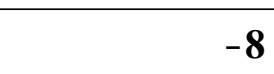 \\
\hline 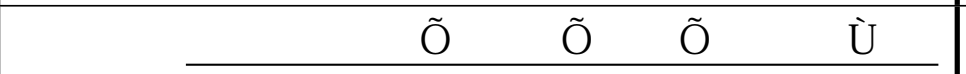 & $\hat{\mathbf{w}}-9$ \\
\hline 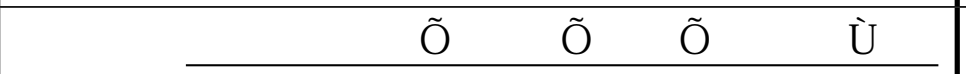 & 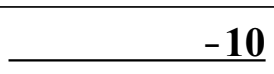 \\
\hline 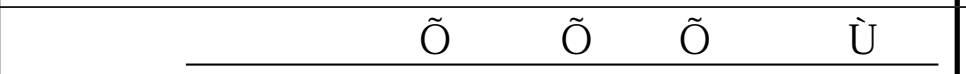 & 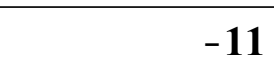 \\
\hline 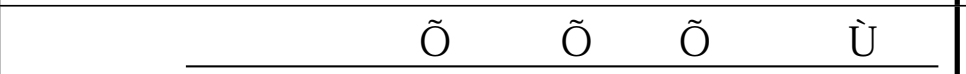 & Řğ்́n12 \\
\hline 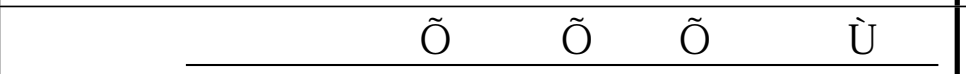 & E13 \\
\hline 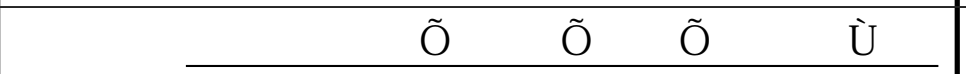 & Eat:5 \\
\hline 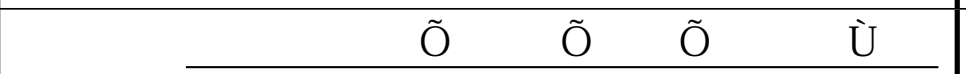 & 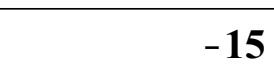 \\
\hline 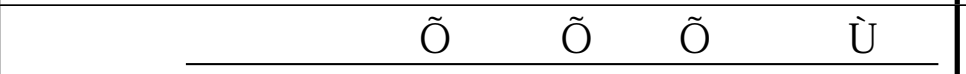 & $\overline{\mathbf{F} 16}$ \\
\hline 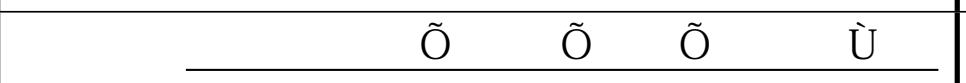 & $\varepsilon t^{\prime}(2)=E^{\prime}-17$ \\
\hline 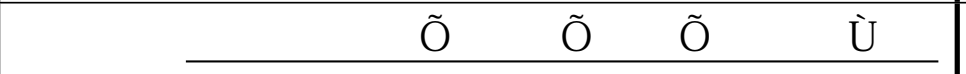 & țūs - 18 \\
\hline 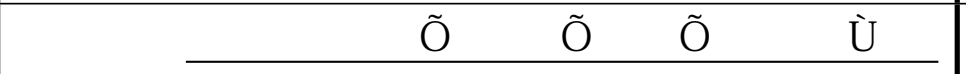 & UE19 \\
\hline 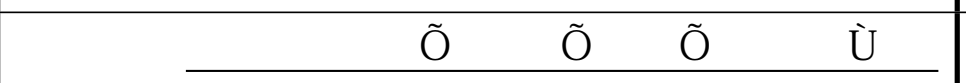 & E20 \\
\hline 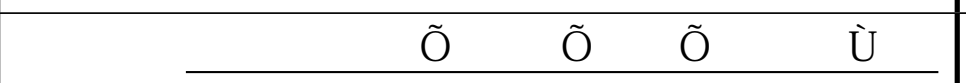 & Ŕgí \\
\hline 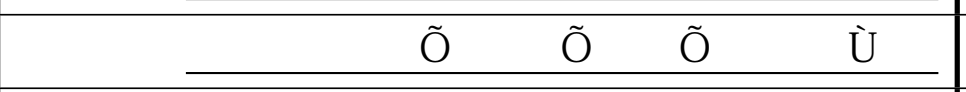 & $\mathbf{B}^{\prime} \mathbf{K}$ \\
\hline 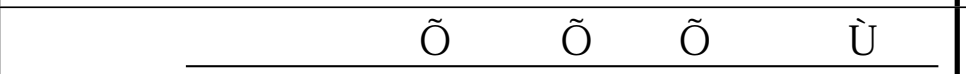 & 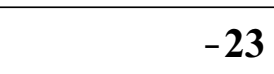 \\
\hline 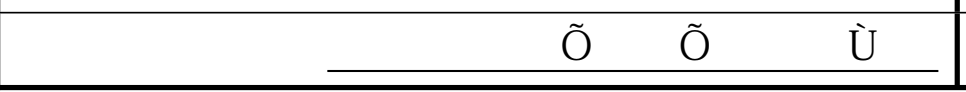 & ũ Q⿳⺈冂: 24 \\
\hline
\end{tabular}

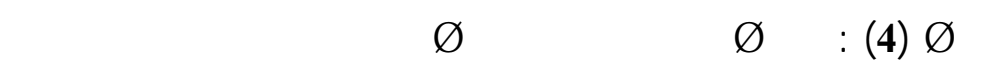

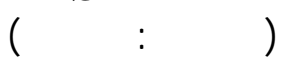




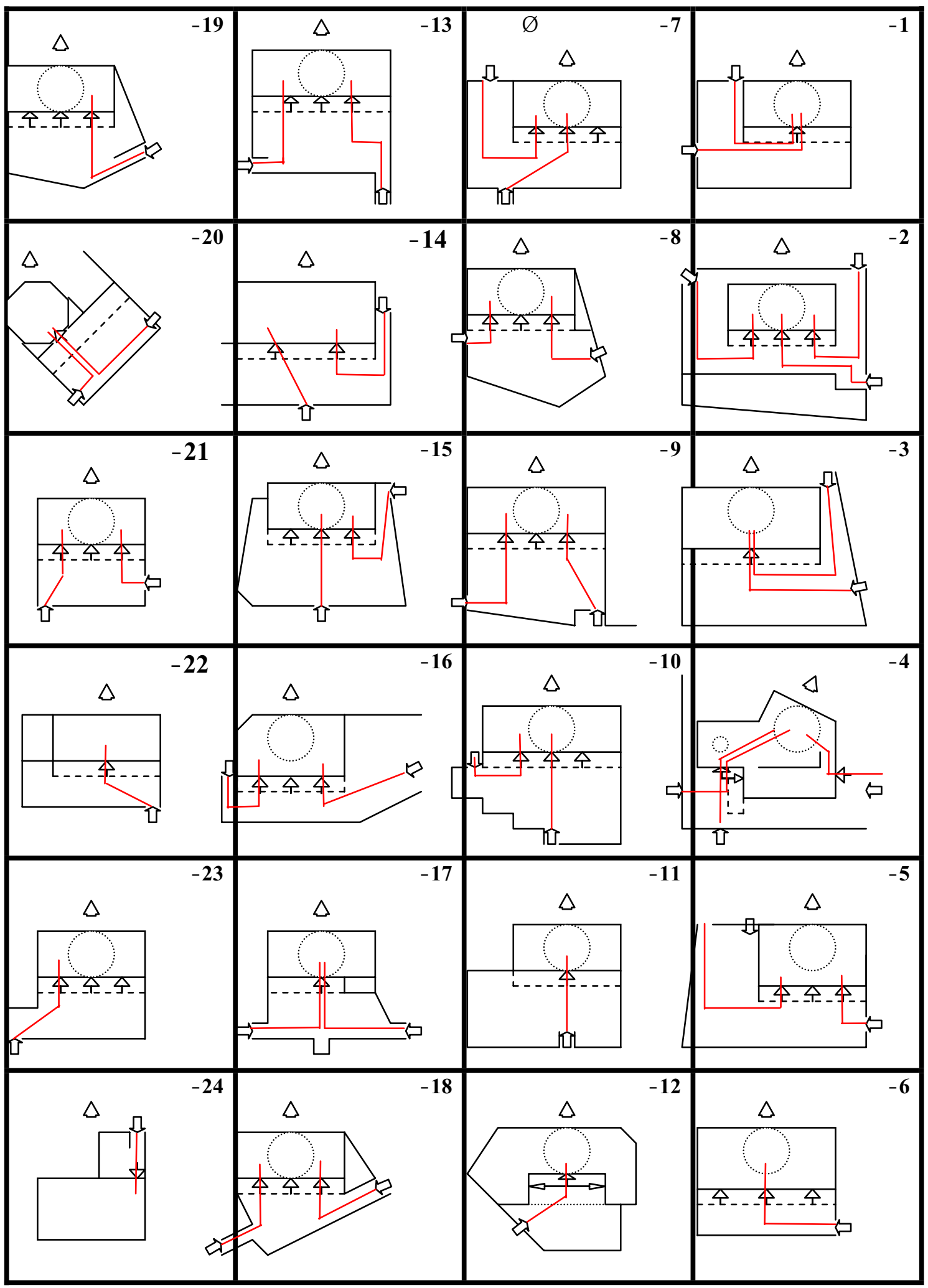

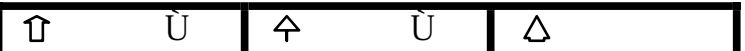

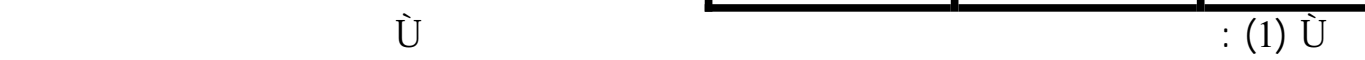




\begin{tabular}{llll} 
Al-Rafidain Engineering & Vol.14 & No.3 & 2006 \\
\hline
\end{tabular}

$46 \%$
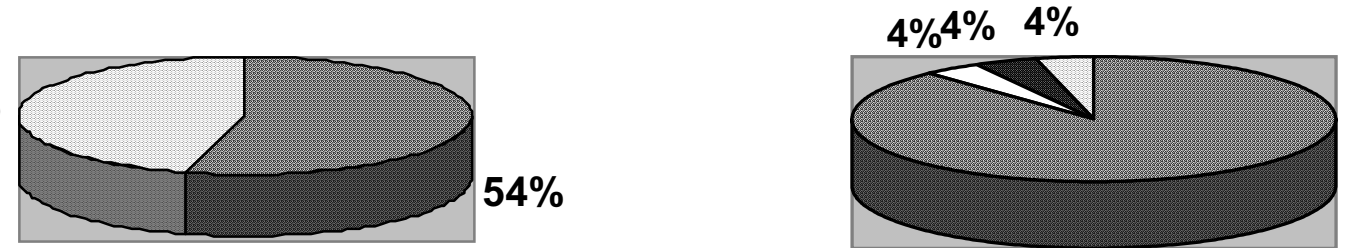

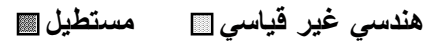

$88 \%$

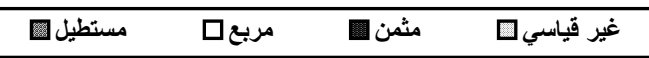

\begin{tabular}{|c|c|}
\hline $\begin{array}{l}\text { tfźfū́td } \\
\text { Fǘge }\end{array}$ & 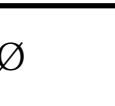 \\
\hline 11 & 13 \\
\hline
\end{tabular}

: (3) 3/20 (6) 3/gt's

\begin{tabular}{|c|c|c|c|c|}
\hline Fūgettź & (\$) & V̂t: & 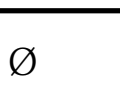 & 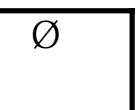 \\
\hline 1 & 1 & 1 & 22 & 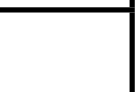 \\
\hline
\end{tabular}

$4 \%$

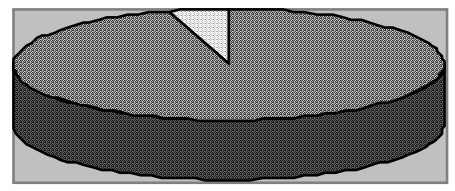

$96 \%$

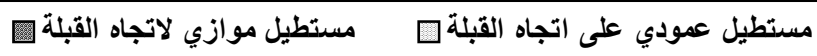

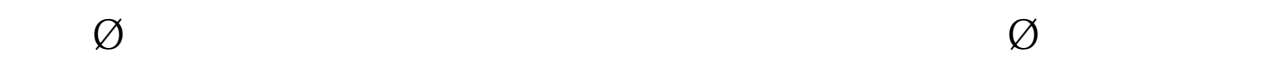

\begin{tabular}{|c|c|c|}
\hline 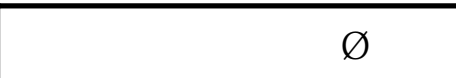 & rtthing & 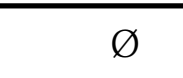 \\
\hline 1 & 22 & V̂GShitîn \\
\hline
\end{tabular}

: (4) ¿

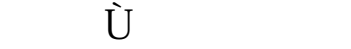
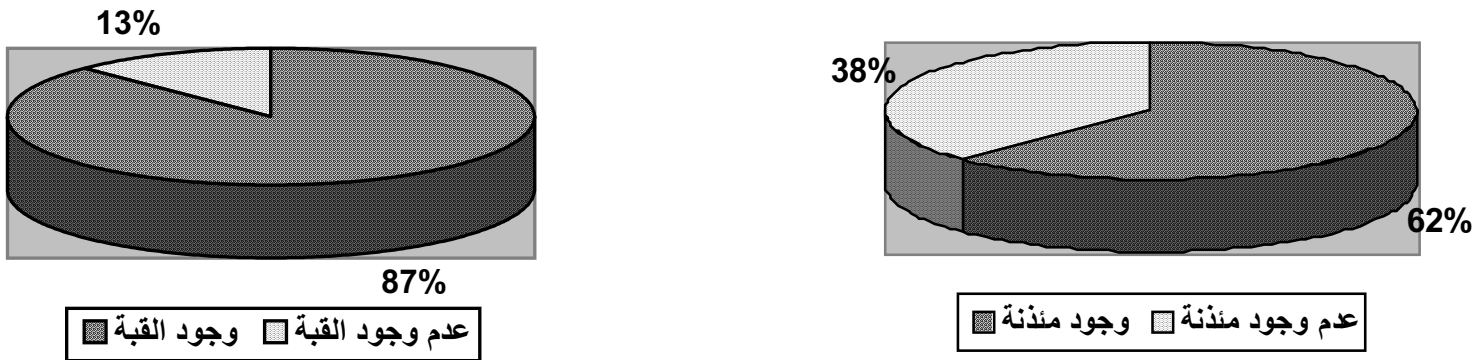

صام وجود مئذنة ص وجود مئذنة

\begin{tabular}{|c|c|c|}
\hline 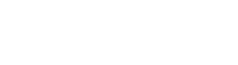 & nitroligs & 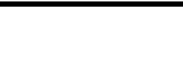 \\
\hline 3 & 21 & 守 \\
\hline
\end{tabular}

: (6) 3/4̆g (9) 3/gt's

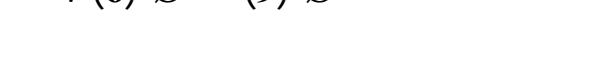

\begin{tabular}{|c|c|c|}
\hline raditgsg 1 tîn & rciditgsg & rctore \\
\hline 9 & 15 & Vogsintiồ \\
\hline
\end{tabular}

: (5) 3/2ug (8) 3/gt's

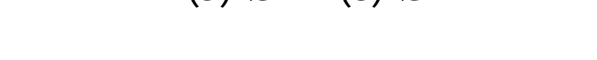



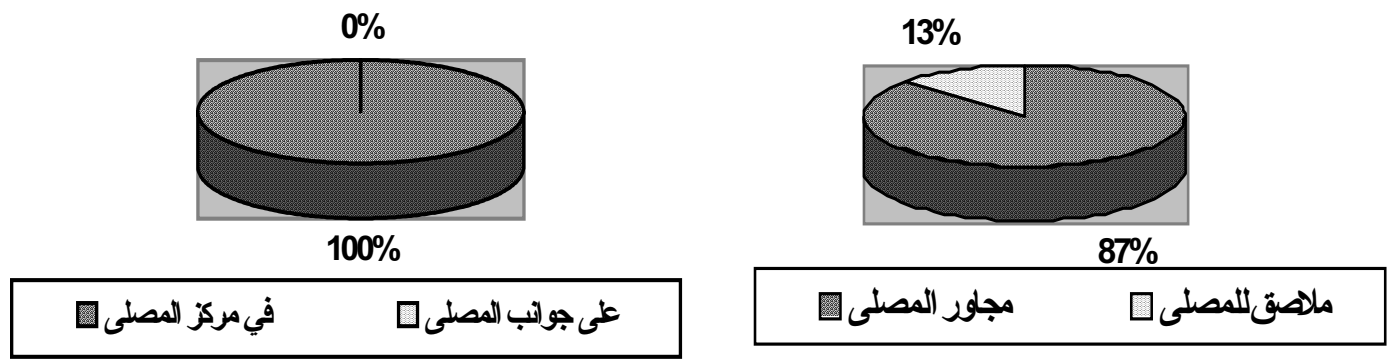

\begin{tabular}{|c|c|c|}
\hline 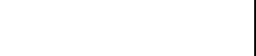 & Qดว & 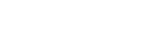 \\
\hline 0 & 22 & Ŕct'titî́ \\
\hline
\end{tabular}

\begin{tabular}{|c|c|c|}
\hline 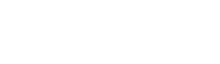 & ว 2 & 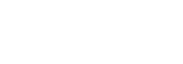 \\
\hline 2 & 13 & ćfbritîn \\
\hline
\end{tabular}

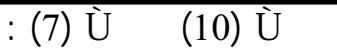
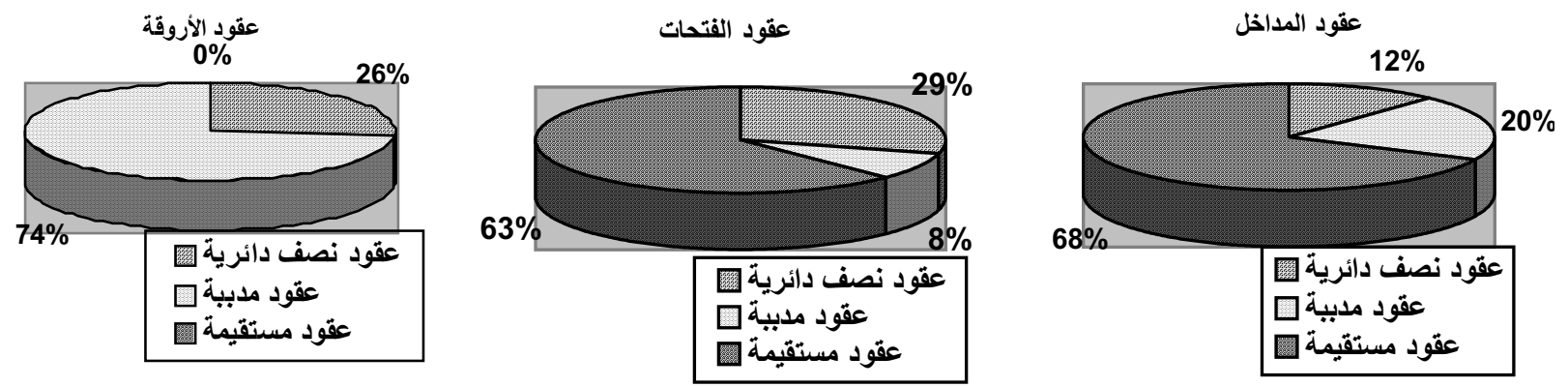

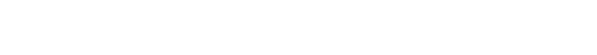

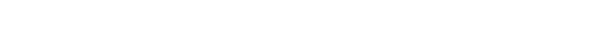

\begin{tabular}{|c|c|c|c|}
\hline 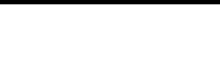 & nút't'tón̂े & 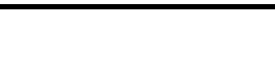 & t'gâingec \\
\hline$\overline{17}$ & 5 & 3 & 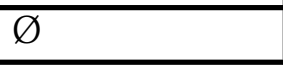 \\
\hline 15 & $\overline{2}$ & 7 & 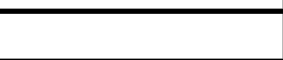 \\
\hline$\notin \bar{Z}$ & 14 & $\overline{5}$ & 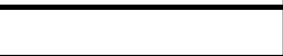 \\
\hline
\end{tabular}

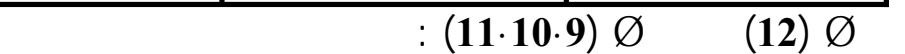

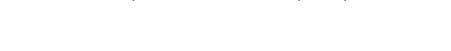

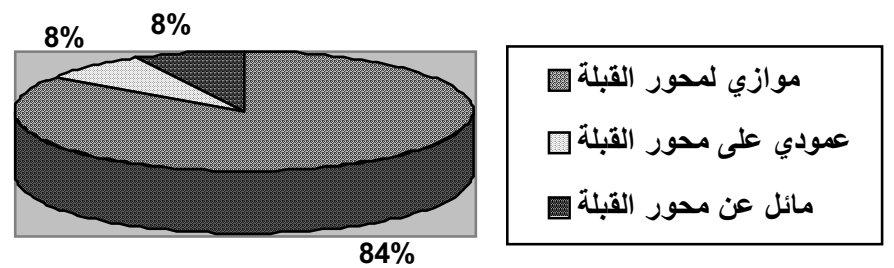

\begin{tabular}{|c|c|c|c|}
\hline 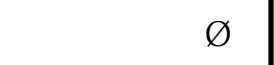 & 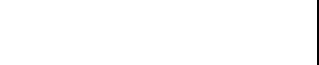 & 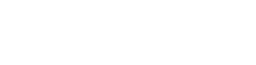 & 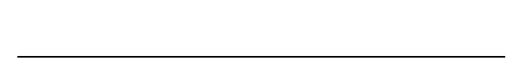 \\
\hline 2 & 2 & 22 & V̂agrotitî \\
\hline
\end{tabular}

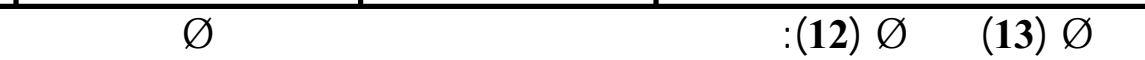

